\title{
OMEGA-3 FATTY ACIDS AND CARDIOVASCULAR DISEASE: EPIDEMIOLOGY AND EFFECTS ON CARDIOMETABOLIC RISK FACTORS
}

\author{
Trevor A Mori
}

\begin{abstract}
School of Medicine and Pharmacology, Royal Perth Hospital Unit, University of Western Australia and the Cardiovascular Research Centre, Perth, Western Australia, Australia.
\end{abstract}

Address correspondence and reprint requests to:

Professor Trevor A Mori, School of Medicine and Pharmacology, Medical Research Foundation Building, Box X 2213 GPO, Perth, Western Australia 6847.

Telephone: 61892240273

Fax: 61892240246

Email: trevor.mori@uwa.edu.au 


\section{ABSTRACT}

Clinical and epidemiological studies provide support that the polyunsaturated omega-3 fatty acids eicosapentaenoic acid and docosahexaenoic acid from fish and fish oils are cardioprotective, particularly in the setting of secondary prevention. Omega-3 fatty acids benefit multiple cardiometabolic risk factors including lipids, blood pressure, vascular reactivity and cardiac function, as well as having antithrombotic, anti-inflammatory and antioxidative actions. Omega-3 fatty acids do not associate with any adverse effects and do not adversely interact with prescriptive drugs such as lipid-lowering, antihypertensive or hypoglycaemic medications. Clinical studies suggest that doses up to $4 \mathrm{~g}$ daily when prescribed with anticoagulant or antiplatelet drugs do not associate with increased risk of major bleeding episodes. Omega-3 fatty acids have gained widespread usage by general practitioners and clinicians in clinical settings such as pregnancy and infant development, secondary prevention in coronary heart disease patients and treatment of dyslipidaemias. Health authorities currently recommend an intake of at least two oily fish meals per week for the general population which equates to approximately $500 \mathrm{mg}$ per day of eicosapentaenoic acid and docosahexaenoic acid. In patients with coronary heart disease the guidelines recommend $1 \mathrm{~g}$ daily supplements and in hypertriglyceridaemic patients up to $4 \mathrm{~g}$ per day. These doses are now achievable with readily available purified encapsulated preparations of omega-3 fatty acids. However, a more practical recommendation for increasing omega-3 fatty acid intake in the general population is to incorporate fish as part of a healthy diet that includes increased consumption of fruits and vegetables, and moderation of salt intake. 


\section{INTRODUCTION}

Observational studies first reported in the 1970s showed that the Greenland Inuit population had a low incidence of coronary artery disease that was related to their traditional lifestyle and in particular their distinctive dietary habits ${ }^{1-3}$. The Inuit population was found to have a reduced prevalence of other chronic and inflammatory diseases such as arthritis, psoriasis, asthma and diabetes. The traditional Greenland Inuit diet derived its main energy source from cold water marine fish and artic mammals such as seal and whale. Thus in comparison with a typical Western diet, it contained much higher protein and fat (approx 40\% energy) and lower

carbohydrates $^{2}$, but also substantially higher amounts of omega-3 ( $\left.\omega 3\right)$ polyunsaturated fats,

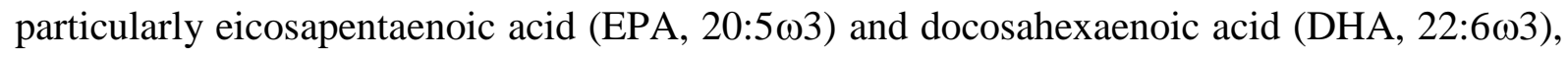

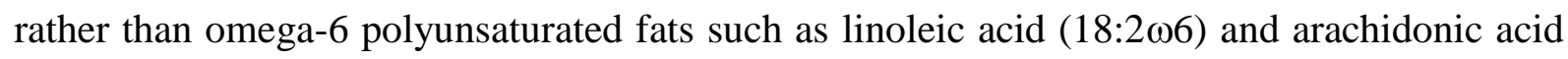

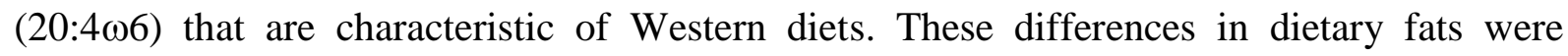
consistent with the plasma fatty acid profile of the Inuit population. The metabolic consequences of the Inuit diet included a more favourable lipid and lipoprotein profile, typically lower levels of triglycerides, cholesterol, low density lipoprotein cholesterol (LDLC) and very low density lipoprotein cholesterol (VLDL-C), and higher concentrations of high density lipoprotein cholesterol (HDL-C); prolongation of bleeding times; reduced platelet aggregability and thrombosis; and altered eicosanoid profile due to the higher plasma EPA and reduced arachidonic acid levels ${ }^{1-3}$.

\section{FATTY ACIDS: SOURCES, BIOCHEMISTRY AND METABOLISM}

$\omega 3$ and $\omega 6$ Fatty acids are essential polyunsaturated fatty acids derived from linoleic acid

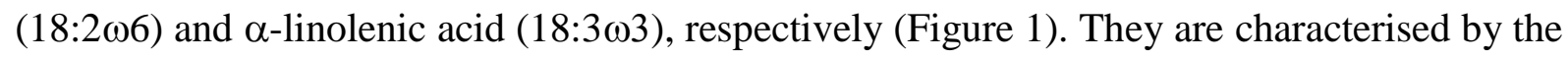
presence of the first double bond at the third carbon or sixth carbon, respectively, from the methyl terminus of the fatty acid chain. Chain elongation and desaturation of linoleic and $\alpha-$ 
linolenic acids leads to the formation of arachidonic acid and EPA, respectively. Both of these fatty acids are substrates for the cyclooxygenase, lipoxygenase and cytochrome P450 enzymes, yielding eicosanoids with varying physiological functions. Further elaboration of EPA yields the 22-carbon fatty acid DHA. The eicosanoids derived from EPA have been shown to be generally less biologically active than those from arachidonic acid ${ }^{4}$, or they antagonise the action of those metabolites derived from arachidonic acid ${ }^{5}$.

Western diets are abundant in $\omega 6$ fatty acids, mainly derived from vegetable oils rich in linoleic acid. $\alpha$-Linolenic acid is found in some plant oils particularly linseed oil $(\sim 53 \%)$, rapeseed oil (canola oil contains $\sim 10 \%$ ), soybean oil $(\sim 7 \%)$ and walnut oil $(\sim 10 \%)$. Humans lack the necessary enzymes to convert $\omega 6$ fatty acids to $\omega 3$ fatty acids and have a limited capacity $(<1 \%)$ to convert $\alpha$-linolenic acid to EPA and DHA ${ }^{6}$. Thus the main dietary source of $\omega 3$ fatty acids is fish especially oily fish species, shell fish and fish oils.

The lipid composition of fish is highly variable between fish species. Diet, season, latitude, temperature, age, sex and size, also influence lipid content and composition. Fish species with relatively high $\omega 3$ fatty acid content include oily fish such as mackerel, salmon, cod, mullet, herring and flounder ${ }^{7}$.

Since these reports of more forty years ago numerous population studies and clinical trials, as well as animal experimental studies, have examined the role of $\omega 3$ fatty acids in various disease states. The purpose of this review is to examine the evidence for an effect of $\omega 3$ fatty acids, specifically EPA and DHA, on cardiovascular disease in humans. Data from in vitro and animal studies will be considered where it assists to understand possible mechanisms of action of $\omega 3$ fatty acids. The review will not address any potential effects of $\alpha$-linolenic acid. 


\section{$\omega 3$ FATTY ACIDS: EVIDENCE FROM POPULATION STUDIES AND}

RANDOMISED CONTROLLED TRIALS

\section{Population Studies}

A number of population studies have demonstrated an inverse association between consumption of $\omega 3$ fatty acids as fish or fish oils and cardiovascular disease. These findings have been confirmed in several meta-analyses ${ }^{8-14}$. Bucher et al ${ }^{8}$ examined randomised controlled trials that compared dietary or non-dietary intake of $\omega 3$ fatty acids in patients with coronary heart disease (CHD). In an analysis comprising eleven studies that included 15,806 patients, $\omega 3$ fatty acids associated with a risk ratio of 0.7 for fatal myocardial infarction ( $\mathrm{P}<0.001), 0.7$ for sudden death $(\mathrm{P}<0.01)$ and 0.8 for overall mortality $(\mathrm{P}<0.001)$. Whelton et al $^{11}$ in 19 studies (14 cohort and 5 case-control) comprising 228,864 participants, showed that fish consumption associated with a relative risk of 0.83 for fatal $\mathrm{CHD}(\mathrm{P}<0.005)$ and 0.86 for total CHD $(\mathrm{P}<0.005)$. He et al ${ }^{9}$ reported an inverse and dose-dependent relationship between fish consumption and CHD mortality. Analysis included 13 cohorts with 222,364 individuals and an average 11.8 years follow-up. Compared with those who either never consumed fish or ate less than one fish meal per month, the relative risks for CHD mortality were 0.89 for fish intake 1-3 times per month, 0.85 for once a week, 0.77 for 2-4 times per week, and 0.62 for 5 or more times per week. The authors estimated a 7\% reduced risk of CHD mortality for every $20 \mathrm{~g} /$ day increase in fish intake $(\mathrm{P}=0.03)$. Wang et al ${ }^{10}$ in a meta-analysis comprising primary and secondary prevention trials and cohort studies in patients receiving fish oil supplements or consuming diets containing fish, reported evidence for benefits of $\omega 3$ fatty acids, particularly in the setting of secondary prevention. Fish consumption associated with lower rates of all-cause mortality, myocardial infarction, cardiac and sudden death.

Marik et al ${ }^{12}$ analysed 11 studies that included 39,044 patients randomized to dietary supplements of EPA/DHA that were administered for at least 1 year. Patients included those 
that had a recent myocardial infarction, those with an implanted cardioverter defibrillator, and patients with heart failure, peripheral vascular disease, and hypercholesterolaemia. The average dose of EPA/DHA was $1.8 \pm 1.2 \mathrm{~g} /$ day and the mean duration of follow-up was $2.2 \pm 1.2$ years. The authors showed $\omega 3$ fatty acids reduced the risk of cardiovascular deaths (odds ratio $[\mathrm{OR}]=0.87, \mathrm{P}=0.002)$, sudden cardiac death $(\mathrm{OR}=0.87, \mathrm{p}=0.04)$, all-cause mortality $(\mathrm{OR}=0.92, \mathrm{P}=0.02)$ and nonfatal cardiovascular events $(\mathrm{OR}=0.92, \mathrm{P}=0.02)$. In a meta-analysis of 8 studies, Musa-Veloso et al ${ }^{13}$ examined the effect of $\omega 3$ fatty acids using an arbitrary cut-off $\geq 250 \mathrm{mg} /$ day compared with $<250 \mathrm{mg} /$ day, on the risk of fatal and non-fatal CHD in individuals with no prior history of CHD. Consumption $\geq 250 \mathrm{mg} / \mathrm{d}$ associated with a $35.1 \%$ reduction in the risk of sudden cardiac death $(\mathrm{P}<0.001)$ and a $16.6 \%$ reduction in the risk of total fatal coronary events $(\mathrm{P}=0.08)$, but the risk of non-fatal myocardial infarction was not significantly reduced. The authors went on to suggest an intake of $250 \mathrm{mg} / \mathrm{day}$ of $\omega 3$ fatty acids may be a minimum target to be achieved by the general population for the promotion of cardiovascular health. Zhao et al ${ }^{14}$ analysed 8 randomized controlled trials that compared dietary or supplementary $\omega 3$ fatty acids in 20,997 patients with CHD. In patients with prior myocardial infarction, $\omega 3$ fatty acids reduced the relative risk of sudden cardiac death $(0.43$, $\mathrm{P}=0.03)$. The relative risk for cardiac death and all-cause mortality were $0.57(\mathrm{P}=0.01)$ and $0.66(\mathrm{P}=0.02)$, respectively.

In contrast to the above analyses demonstrating benefit, Rizos et al ${ }^{15}$ reported $\omega 3$ fatty acids did not associate with a lower risk of all-cause mortality, cardiac death, sudden death, myocardial infarction or stroke, in a meta-analysis comprising 20 studies of 68,680 patients. The observed effect was not associated with study specific or population-specific characteristics. Although the relative risks for cardiac death and sudden death were 0.91 $(\mathrm{P}=0.01)$ and $0.87(\mathrm{P}=0.06)$, respectively, the authors adopted a conservative statistical approach and inexplicably set the p-value for significance at 0.0063 . Two other recent meta- 
analyses have shown no overall benefits of $\omega 3$ fatty acids on cardiovascular events ${ }^{16,17}$.

Population studies have shown that increased consumption of $\omega 3$ fatty acids as fatty fish associated with lower rates of heart failure, albeit unexpectedly in one study the relationship was U-shaped suggesting higher consumption did not provide additional benefit ${ }^{18}$. Djousse et al ${ }^{19}$, in a meta-analysis comprising 176,441 subjects and 5,480 incident cases of heart failure from 7 prospective studies, showed the pooled relative risk for heart failure comparing the highest to lowest category of fish intake was $0.85(\mathrm{p}=0.04)$ and for $\omega 3$ fatty acids was 0.86 $(p=0.05)$. Mozaffarian et $a^{20}$ showed consumption of tuna or other broiled or baked fish, but not fried fish associated with a lower incidence of heart failure.

The effects of $\omega 3$ fatty acids on atrial fibrillation in population studies are equivocal with some studies showing benefit ${ }^{21-23}$ whilst others have shown no effect ${ }^{24,25}$. Recent reports have suggested there may be a U-shaped relationship between $\omega 3$ fatty acids and atrial fibrillation ${ }^{26,27}$. Metcalf et al ${ }^{26}$ examined the relationship between red blood cell $\omega 3$ fatty acids and the incidence of postoperative atrial fibrillation lasting $>10 \mathrm{~min}$ in the first 6 days following surgery. They showed that patients in the lowest and highest quintiles of red blood cell DHA had significantly higher risk of developing postoperative atrial fibrillation compared with those in the fourth quintile ( $\mathrm{OR}=2.36$ and $\mathrm{OR}=2.45$, respectively). There was no association between EPA levels and postoperative atrial fibrillation incidence. In a cohort study comprising 57,053 Danish participants aged 50-64 years, Rix et al ${ }^{27}$ showed a Ushaped relationship between $\omega 3$ fatty acid intake assessed from food frequency questionnaires and risk of atrial fibrillation. There was a $13 \%$ lower risk of atrial fibrillation in the middle compared with the lowest and highest quintiles $(\mathrm{P}=0.02)$ of $\omega 3$ fatty acid intake, with the lowest risk close to the median intake of $0.63 \mathrm{~g} / \mathrm{day}$.

Several meta-analyses have shown an inverse association between increased intake of $\omega 3$ fatty acids and risk of stroke, particularly ischemic stroke ${ }^{28,29}$. He at al ${ }^{28}$ reported that 
compared with individuals that never consumed fish or ate fish less than once per month, the relative risks for total stroke were 0.91 for those with fish intake 1-3 times per week, 0.87 for once per week, 0.82 for 2-4 times per week and 0.69 for five or more times per week. In analyses that examined stroke subtypes, the protective effects were only evident with ischaemic stroke. In an analysis of 19 cohort studies including 402,127 individuals, Xun et al ${ }^{29}$ reported a relative risk of 0.91 for total stroke in those who ate 2-4 fish meals per week relative to those that ate less than one fish meal per month. As in previous reports, the protective effect was only evident with ischaemic stroke.

\section{Randomised Controlled Trials}

Several large randomised controlled trials have shown $\omega 3$ fatty acids provide benefit, particularly in patients with CHD. The Diet and Reinfarction Trial (DART) conducted in 2,033 men with recent myocardial infarction showed $\omega 3$ fatty acids consumed as oily fish or fish oil capsules reduced all-cause mortality by $29 \%^{30}$. The Gruppo Italiano per lo Studio della Sopravvivenza nell'Infarto (GISSI) study randomised 11,323 post-myocardial infarction patients to a daily capsule containing $850 \mathrm{mg} \omega 3$ fatty acids or usual care ${ }^{31}$. After one year, patients receiving $\omega 3$ fatty acids had a $21 \%, 30 \%$ and $45 \%$ reduction in total and cardiovascular mortality, and sudden cardiac death, respectively. The same investigators showed in a follow-up study in nearly 7,000 patients with class II to IV heart failure (GISSI$\mathrm{HF}$, that $850 \mathrm{mg} /$ day of $\omega 3$ fatty acids significantly reduced total mortality by $9 \%$ and total mortality or hospitalisation for cardiovascular diseases by $8 \%^{32}$. The Japan EPA Lipid Intervention Study (JELIS), randomised 18,645 hypercholesterolaemic patients to either statin or statin plus $1800 \mathrm{mg} /$ day of purified EPA ${ }^{33}$. After 5 years, there was a $19 \%$ reduction in major cardiovascular events in patients randomised to EPA.

In contrast to the above studies demonstrating benefits of $\omega 3$ fatty acids on cardiovascular outcomes, several other randomised controlled interventions have failed to 
show any benefits of $\omega 3$ fatty acids. The OPERA study that included 1,516 patients undergoing cardiac surgery, showed $840 \mathrm{mg} /$ day $\omega 3$ fatty acids did not reduce the risk of postoperative atrial fibrillation relative to placebo ${ }^{34}$. The ORIGIN trial ${ }^{35}$ in 12,536 patients with or at high risk for diabetes, showed that during a median follow-up of 6.2 years $900 \mathrm{mg} / \mathrm{day}$ of $\omega 3$ fatty acids did not reduce the rate of cardiovascular events. In a trial of 12,513 patients with multiple cardiovascular risk factors or atherosclerotic vascular disease but not myocardial infarction, $\omega 3$ fatty acids did not reduce cardiovascular mortality and morbidity ${ }^{36}$.

The reasons for divergent results between studies are not clear but may relate to a number of important factors. Firstly, $\omega 3$ fatty acids may well provide greater benefit to patients with recent myocardial infarction or heart failure due to their antiarrhythmic effects. Secondly, it may be that some studies have had limited power to detect a reduction in sudden deaths from cardiac causes or arrhythmic events. Other important factors include studies using doses of $\omega 3$ fatty acids that are lower than the 800-900 mg/day previously shown to have an effect, the presence of confounding comorbidities, effects of concomitant medications and the likelihood that recent studies have included patients that are already receiving a high level of clinical care. Results may also be confounded by the effects of dietary background, particularly in relation to $\omega 3$ fatty acid intake. In this regard, studies may have included participants with a relatively high intake of $\omega 3$ fatty acids. Such participants would likely have higher cellular levels of $\omega 3$ fatty acids levels, thus limiting the likelihood of detecting additional benefits of $\omega 3$ fatty acid supplementation. Some investigators have also suggested cardiovascular benefits may be dependent on the ratio of dietary $\omega 6$ to $\omega 3$ fatty acids. However, Harris et al ${ }^{37}$ showed absolute intake of $\omega 3$ fatty acids is more important than the ratio of their intake to $\omega 6$ fatty acids. Harris et al ${ }^{37}$ also suggested tissue $\omega 3$ fatty acid levels are more prognostic and diagnostic in coronary artery disease assessment. 


\section{Ф3 FATTY ACIDS AND CARDIOMETABOLIC RISK FACTORS}

There is considerable evidence that EPA and DHA have independent effects on numerous physiological pathways, and collectively they provide protection against CHD, particularly sudden coronary death ${ }^{38-41}$. EPA and DHA beneficially affect multiple cardiometabolic risk factors including blood pressure ${ }^{42-45}$ and cardiac function ${ }^{41,44}$, arterial compliance ${ }^{46,47}$, vascular reactivity ${ }^{48,49}$ and lipids ${ }^{50,51}$, as well as having anti-platelet ${ }^{52}$, anti-inflammatory ${ }^{53-55}$, pro-resolving ${ }^{56}$ and anti-oxidative actions ${ }^{57}$. Trials in humans using highly purified oils have also highlighted that EPA and DHA have differential effects on blood pressure, heart rate, lipids and vascular reactivity ${ }^{58}$.

The following sections review the effects of $\omega 3$ fatty acids on cardiometabolic risk factors, concentrating particularly on evidence from randomised controlled studies in humans. Some data from experimental and animal studies will be considered where it assists to understand possible mechanisms of action of $\omega 3$ fatty acids.

\section{Plasma Lipids}

$\omega 3$ Fatty acids reduce triglycerides in a dose-dependent manner across a wide range of $\omega 3$ fatty acid consumption ${ }^{41}$. Intakes of approximately $4 \mathrm{~g} /$ day reduce serum triglycerides by 25-30\%. Mozaffarian et al ${ }^{41}$ determined that plasma triglycerides are reduced by $0.33 \mathrm{mmol} / \mathrm{L}$ for a 1g/day increase in EPA plus DHA. In trials supplementing highly purified EPA or DHA, Mori et al 59, 60 further showed the triglyceride-lowering actions of $\omega 3$ fatty acids were attributable to both EPA and DHA. High-doses of $\omega 3$ fatty acids can be useful as adjunct therapy in the treatment of hypertriglyceridaemia.

The fall in plasma triglycerides following $\omega 3$ fatty acid consumption is due in part to a reduction in hepatic very-low density lipoprotein cholesterol (VLDL) synthesis. Mechanisms for this effect include reduced fatty acid availability for triglyceride synthesis as a result of decreased de novo lipogenesis, a reduction in the delivery of non-esterified fatty acids to the 
liver, increased fatty acid $\beta$-oxidation, altered enzymatic activity for triglyceride assembly in the liver, and increased hepatic synthesis of phospholipids instead of triglycerides $50,51,61$. Cussons et al ${ }^{62}$ also showed that $\omega 3$ fatty acids significantly reduced liver fat by $18 \%$ in women with hepatic steatosis.

$\omega 3$ Fatty acids have very little effect on total cholesterol and LDL-C ${ }^{50,51}$. However, Mori et al showed in overweight, treated hypertensive patients ${ }^{63}$ and in dyslipidaemic men ${ }^{59}$, that $\omega 3$ fatty acids had a small, albeit significant effect on increasing HDL-C, due primarily to an increase in the $\mathrm{HDL}_{2}-\mathrm{C}$ subfraction.

A small, but significant increase in LDL-C in studies supplementing $\omega 3$ fatty acids associated with an increase in LDL particle size. Mori et al ${ }^{59,64}$ showed that DHA but not EPA supplementation increased LDL particle size. Studies have shown that reduced LDL particle size is an important cardiovascular risk factor ${ }^{65}$ that correlates with sub-clinical atherosclerosis as measured by intima-media thickening ${ }^{66}$.

A number of clinical trials have shown that $\omega 3$ fatty acids may compliment lipid lowering therapy in dyslipidaemic patients. Chan et al ${ }^{67}$ showed in dyslipidaemic, viscerally obese men with insulin resistance, that supplementation with $\omega 3$ fatty acids in addition to statin therapy resulted in optimal changes in lipid profile as reflected by decreased plasma triglycerides and increased HDL-C.

\section{Blood Pressure}

\section{$\underline{\text { Meta-Analyses }}$}

Randomised controlled trials in which participants have been provided fish meals or supplemented fish oils unequivocally demonstrate that $\omega 3$ fatty acids lower blood pressure. Three meta-analyses have investigated the effect of $\omega 3$ fatty acids on blood pressure ${ }^{42,43,45}$. In an analysis of 31 placebo controlled trials involving 1,536 subjects, Morris et al ${ }^{45}$ showed a reduction in blood pressure of $-3.0 /-1.5 \mathrm{mmHg}$ with an average dose of $4.8 \mathrm{~g} /$ day $\omega 3$ fatty 
acids. The blood pressure-lowering effects were strongest in treated and untreated hypertensive individuals (a fall of $-3.4 /-2.0 \mathrm{mmHg}$ ) whereas there was no significant change in normotensive subjects. The authors predicted blood pressure was reduced $-0.66 /-0.35$ $\mathrm{mmHg}$ for each $1 \mathrm{~g} /$ day increase in $\omega 3$ fatty acids. The dose response effect was greater for DHA than for EPA. Appel et al ${ }^{42}$ reported blood pressure fell $-5.5 /-3.5 \mathrm{mmHg}$ in untreated hypertensive individuals and $-1.0 /-0.5 \mathrm{mmHg}$ in normotensives with an average consumption of more than $3 \mathrm{~g} /$ day of $\omega 3$ fatty acids. Geleijnse et al ${ }^{43}$ examined 36 trials that included approximately $50 \%$ of participants with hypertension (systolic blood pressure $\geq 140 \mathrm{mmHg}$ and/or diastolic blood pressure $\geq 90 \mathrm{mmHg}$ ), a mean trial duration of 11.7 years and a median dose of $3.7 \mathrm{~g} /$ day $\omega 3$ fatty acids. Overall, $\omega 3$ fatty acids reduced blood pressure by $-2.1 /-1.6$ mmHg. The greatest effects on blood pressure were observed in individuals older than 45 years (a fall of -3.5/-2.4 $\mathrm{mmHg}$ ) and those that were hypertensive $(\geq 140 / 90 \mathrm{mmHg}$ ) (a fall of 4.0/-2.5 $\mathrm{mmHg}$.

$\underline{\omega 3 \text { Fatty Acids and Antihypertensive Medication or Lifestyle Modification }}$

It is noteworthy that not all studies have demonstrated a reduction in blood pressure with consumption of fish or $\omega 3$ fatty acid supplementation. The reasons for this are likely related to differences in study design, the protocol and choice of instrument used for blood pressure assessment, studies with relatively small sample size leading to a lack of statistical power and/or studies that have employed a dose of $\omega 3$ fatty acids not sufficiently high to elicit an effect. In regard to the latter, Dokholyan et al ${ }^{68}$ reported low doses of $\omega 3$ fatty acids were ineffective in reducing blood pressure in patients with high-normal diastolic blood pressure or stage 1 hypertension. The authors concluded that doses greater than $3 \mathrm{~g} / \mathrm{day} \omega 3$ fatty acids are required for blood pressure reduction.

Dickinson et al ${ }^{69}$ in a meta-analysis that included 105 trials randomizing 6,805 participants, examined the efficacy of a number of dietary nutrients and lifestyle in patients 
with a mean baseline blood pressure of $147 / 92 \mathrm{mmHg}$ and a mean age of 50 years. $\omega 3$ Fatty acids at a dose 0.1-1.7 g/day reduced blood pressure by -2.3/-2.2 $\mathrm{mmHg}$. These effects were, however, modest in comparison with the estimated benefits of improved diet (-5.0/-3.7 $\mathrm{mmHg}$ ), sodium restriction $(-3.6 /-2.5 \mathrm{mmHg})$, aerobic exercise $(-4.6 /-2.4 \mathrm{mmHg})$ and alcohol restriction $(-3.8 /-3.2 \mathrm{mmHg})$.

Randomised controlled studies have shown the blood pressure-lowering effects of $\omega 3$ fatty acids are potentiated by concomitant lifestyle changes and antihypertensive medication. Cobiac et al ${ }^{70}$ showed that the blood pressure reduction following fish oil supplementation was enhanced by sodium restriction in healthy elderly volunteers. Singer et al ${ }^{71}$ showed in mild-to-moderate male hypertensive individuals that the blood pressure-lowering effect of fish oil was comparable with that of $\beta$-adrenergic receptor blockade and that simultaneous intake of fish oil plus $\beta$-adrenergic receptor blockade was more effective than either modality alone. Lungershausen et al ${ }^{72}$ showed $\omega 3$ fatty acids also potentiated the antihypertensive effects of $\beta$-blockers or diuretics in treated hypertensives.

Bao et al ${ }^{73}$ reported that $\omega 3$ fatty acids were additive to the blood pressure-lowering effects of weight reduction in overweight treated hypertensives. Sixty three men and postmenopausal women aged 54 years with BMI $31 \mathrm{Kg} / \mathrm{m}^{2}$ were randomised to a calorierestricted weight loss program, a daily fish meal that provided approximately $3.65 \mathrm{~g} /$ day $\omega 3$ fatty acids, the two regimens combined, or a control diet, for 12 weeks. At the end of this period all subjects were placed on a weight-stabilizing diet for 4 weeks and continued on fish if they were in those groups. Weight fell on average $5.6 \mathrm{~kg}$ in the two weight-loss groups. Blood pressure was determined using 24-hour blood pressure measurements. Relative to the control group, awake blood pressures fell -6.0/-3.0 mmHg in those patients consuming a daily fish meal, $-5.5 /-2.2$ in the weight loss group and -13.0/-9.3 in individuals that combined the two regimens. 


\section{Independent Effects of EPA and DHA}

Mori et al ${ }^{74}$ have shown that the blood pressure lowering effect of $\omega 3$ fatty acids is differentially affected by EPA and DHA. In overweight, mildly-hypercholesterolaemic patients, 4g/day of highly purified encapsulated DHA, but not EPA, supplemented for 6 weeks, significantly reduced 24-hour blood pressure by $-5.8 /-3.3 \mathrm{mmHg}$ and awake blood pressure by $-3.5 /-2.0 \mathrm{mmHg}$, relative to a control oil (olive oil). These differences in blood pressure response to EPA and DHA were not observed in normotensive healthy men who were given $4 \mathrm{~g}$ daily EPA or DHA for 7 weeks, relative to a corn oil control ${ }^{75}$. The latter study, however, measured clinic and not 24-hour blood pressure. Woodman et al ${ }^{60}$ were also unable to confirm a differential effect of EPA and DHA on blood pressure in treated hypertensive Type 2 diabetic patients. Neither highly purified encapsulated EPA nor DHA given as a $4 \mathrm{~g}$ daily supplement for 6 weeks reduced 24-hour blood pressure. However, this lack of effect on blood pressure in treated hypertensive Type 2 diabetic patients could be related to concomitant use of pharmacologic agents, the presence of glycaemia and increased blood pressure variability in diabetic patients.

\section{Endothelial and Vascular Function}

Data from experimental animal models of endothelial dysfunction ${ }^{48,76,77}$ as well as in normal healthy individuals ${ }^{78}$, and hypercholesterolaemic ${ }^{79}$ and Type 2 diabetic ${ }^{80}$ patients, have shown that $\omega 3$ fatty acids improved vascular function. Studies in rats also confirmed differential effects of EPA and DHA on vascular function ${ }^{81,82}$. Engler et al ${ }^{81}$ showed that in aortic rings EPA and DHA induced endothelium-dependent and independent vasodilation, respectively. Using aortas from spontaneously hypertensive rats (SHR), McLennan et al ${ }^{82}$ demonstrated DHA was also more effective than EPA at inhibiting thromboxane-like vasoconstrictor responses. The authors further suggested that DHA prevented thromboxaneinduced contraction and restored the vasoconstrictor/vasodilator balance following 
impairment of the normal nitric oxide-related processes.

Harris et al ${ }^{83}$ provided indirect evidence for an effect of DHA, but not EPA, on endothelial function in humans by measuring serum and urinary nitrate output. These data, however, are only suggestive of increased nitric-oxide production in endothelial cells, given that nitrates can also derive from other sources.

Mori et al ${ }^{49}$ provided more direct evidence for differential effects of EPA and DHA on vascular function in humans. They showed that the blood pressure changes following supplementation with DHA, but not EPA in dyslipidaemic patients ${ }^{74}$, were accompanied by significant improvements in endothelial and smooth muscle function as well as reduced vasoconstrictor responses, in the forearm microcirculation ${ }^{49}$. Forearm blood flow was measured with venous occlusion, strain-gauge plethysmography to determine endotheliumdependent and -independent vascular function during intra-arterial infusions of acetylcholine which releases nitric oxide endogenously to produce vasodilation; to sodium nitroprusside that acts as a direct nitric oxide donor; and to norepinephrine which causes vasoconstriction by activating $\alpha$-adrenergic receptors on smooth muscle cells. The study showed DHA, but not EPA, improved vasodilator responses to endogenous and exogenous nitric oxide donors and attenuated vasoconstrictor response to noradrenaline ${ }^{49}$. The mechanisms were predominantly endothelium-independent, based on the fact that co-infusion of acetylcholine with $\mathrm{N}^{\mathrm{G}}$ monomethyl-L-arginine (an inhibitor of nitric oxide synthesis) and infusion of nitroprusside, both of which are endothelium-independent, enhanced vasodilatory responses. These data, however, did not preclude an endothelial component in the dilatory responses associated with DHA.

The effects of $\omega 3$ fatty acids, particularly those of DHA on vasoreactivity are, in part, due to incorporation of $\omega 3$ fatty acids into endothelial membranes with consequent increase in membrane fluidity, calcium influx, and endogenous synthesis and release of nitric oxide. 
Incorporation of $\omega 3$ fatty acids into cell membranes could be expected to affect fluidity, flexibility, permeability and function of the membrane and membrane-bound proteins. These changes could in turn alter enzyme activity, receptor affinity and transport capacity of the cell, including synthesis and/or release of nitric oxide. Hashimoto et al ${ }^{84}$ showed DHA had a greater effect than EPA in increasing membrane fluidity of cultured rat thoracic aorta endothelial cells.

Experimental evidence has shown $\omega 3$ fatty acids may have direct effects on receptorstimulated nitric oxide release, as well as enhanced release of vasodilator prostanoids and/or endothelial-derived hyperpolarizing factor ${ }^{85}$. Enhanced vasodilator response to sodium nitroprusside could also be related to increased biotransformation to nitric oxide or increased reactivity of smooth muscle cells to vasorelaxation as a result of decreased calcium influx ${ }^{86}$. The vasodilator effects of $\omega 3$ fatty acids and DHA in particular, may be related to increased basal production of nitric oxide in smooth muscle cells as a result of decreased release of platelet-derived growth factor (PDGF) ${ }^{87}$. PDGF inhibits induction of nitric oxide synthase in vascular smooth muscle cells ${ }^{88}$.

Animal studies suggest the blood pressure-lowering effects of $\omega 3$ fatty acids may relate to their effects on catecholamines and ATP. Hashimoto et al ${ }^{89}$ showed that DHA fed intragastrically to Wistar rats reduced plasma noradrenaline and increased adenyl purines such as ATP, released both spontaneously and in response to noradrenaline from segments of caudal artery. These rats had $44 \%$ lower plasma noradrenaline and attenuated blood pressure. Plasma adenyl purines were significantly inversely associated with blood pressure. The relevance of these data is in the knowledge that ATP causes vasodilation by stimulating the release of nitric oxide from endothelial cells, by a direct action on vascular smooth muscle cells and by hyperpolarizing smooth muscle cells. Therefore, the increase in ATP release from vascular endothelial cells in conjunction with reduced plasma noradrenaline could contribute 
to the fall in blood pressure following $\omega 3$ fatty acids.

\section{Arterial Compliance}

Blood pressure is strongly influenced by arterial compliance, which in turn is affected by endothelial function. Arterial compliance is also an independent risk factor for cardiovascular disease ${ }^{90}$. Studies have shown that $\omega 3$ fatty acids improve arterial compliance. In Type 2 diabetic patients McVeigh et al ${ }^{46}$ showed that compliance in the large arteries and more peripheral vasculature improved significantly after 6 weeks of fish oil compared with olive oil. Nestel et al ${ }^{47}$ also showed that EPA and DHA supplementation improved arterial compliance by $35 \%$ and $27 \%$, respectively, in patients with dyslipidaemia. In a meta-analysis that included ten randomized controlled trials, four using pulse wave velocity and six using arterial compliance measured as capacitance compliance or systemic arterial compliance, Pase et al ${ }^{91}$ showed that $\omega 3$ fatty acids significantly improved both pulse wave velocity and arterial compliance.

\section{Cardiac Function}

\section{$\underline{\text { Heart Rate }}$}

Increased heart rate is a risk factor for cardiovascular death, particularly sudden death

92. Studies have consistently shown that $\omega 3$ fatty acids reduce heart rate $44,73,74,93$ suggesting a significant cardiac component associated with the antihypertensive effects, possibly mediated by effects on cardiac myocytes, autonomic nerve function or $\beta$-adrenoreceptor activity.

Using 24-hour measurement of heart rate, Bao et al ${ }^{73}$ showed in overweight treated hypertensive patients, that awake heart rate was reduced by 4.3 bpm by a daily fish meal, 1.8 bpm following weight loss and $6.1 \mathrm{bpm}$ by a combination of the two regimens, relative to controls. In subsequent studies Mori et al ${ }^{74}$ have shown that heart rate is differentially affected by EPA and DHA. DHA, but not EPA, significantly reduced 24 hour, awake and asleep heart rate by $-3.5,-3.7$ and $-2.8 \mathrm{bpm}$, respectively ${ }^{74}$. Interestingly, EPA resulted in a 
small, albeit non-significant, rise in heart rate. These data are in accordance with those of Grimsgaard et al ${ }^{75}$ in which heart rate was decreased by $2.2 \mathrm{bpm}$ with $4 \mathrm{~g}$ daily DHA supplementation and increased by $1.9 \mathrm{bpm}$ with EPA.

In a meta-analysis of thirty studies, Mozaffarian et al ${ }^{93}$ showed that the overall effect of $\omega 3$ fatty acids was to reduce heart rate by $-1.6 \mathrm{bpm}$, with a greater reduction in those trials where individuals had a baseline heart rate greater than $69 \mathrm{bpm}(-2.5 \mathrm{bpm})$ and in those studies of longer than 12 weeks duration $(-2.5 \mathrm{bpm})$.

Experimental studies have shown that the mechanisms by which $\omega 3$ fatty acids affect heart rate likely relate to their incorporation into myocardial cells and subsequently altering electrophysiological function in a manner that reduces the vulnerability to ventricular fibrillation ${ }^{94}$. The anti-arrhythmic effects of $\omega 3$ fatty acids are due to their ability to inhibit the fast, voltage-dependent sodium current and the L-type calcium currents, and also to modulate potassium channels ${ }^{94}$.

\section{$\underline{\text { Heart Rate Variability }}$}

Studies in humans suggest that $\omega 3$ fatty acids increase heart rate variability in patients at high risk of sudden cardiac death and in healthy individuals ${ }^{95,}{ }^{96}$. Heart rate variability is a surrogate index of autonomic nerve function and low heart rate variability independently predicts cardiovascular disease mortality in patients with coronary artery disease or chronic heart failure ${ }^{97,98}$ and in healthy populations ${ }^{99}$. Xin et al ${ }^{100}$ in a meta-analysis that included fifteen randomised controlled trials showed that short term $\omega 3$ fatty acid supplementation favourably affects the frequency domain of heart rate variability as indicated by enhancement of vagal tone. These data suggest enhanced vagal tone may be an important mechanism underlying the antiarrhythmic effect of $\omega 3$ fatty acids.

\section{Platelet Function and Thrombosis}

The inhibitory effects of $\omega 3$ fatty acids on thrombosis are thought to account partially 
for the associated reduced risk for sudden cardiac death and reduced all-cause mortality 9,30 , 31. The antithrombotic and antiplatelet effects of $\omega 3$ fatty acids are due to modulation of vasodilator and vasoconstrictor prostanoids ${ }^{52}$. Reduced platelet aggregation in vitro following $\omega 3$ fatty acids, particularly at large doses, is likely due to suppressed production of thromboxane $\mathrm{A}_{2}\left(\mathrm{TXA}_{2}\right)$ a vasoconstrictor and aggregator ${ }^{101}$. Knapp et al ${ }^{102}$ showed that in patients with atherosclerosis $\omega 3$ fatty acids decreased $\mathrm{TXA}_{2}$ and increased thromboxane $\mathrm{A}_{3}$ $\left(\mathrm{TXA}_{3}\right)$ the analogous but substantially less biologically active EPA-derived metabolite. Fischer et al ${ }^{103}$ reported $\omega 3$ fatty acids increased prostaglandin $\mathrm{I}_{3}\left(\mathrm{PGI}_{3}\right)$ (also known as prostacyclin) derived from EPA, without a fall in prostaglandin $\mathrm{I}_{2}\left(\mathrm{PGI}_{2}\right)$ which derives from arachidonic acid. $\mathrm{PGI}_{3}$ is equipotent in its vasodilatory and anti-aggregatory activities to $\mathrm{PGI}_{2}$. It has been suggested that an overall increase in total prostacyclin $\left(\mathrm{PGI}_{2}\right.$ and $\left.\mathrm{PGI}_{3}\right)$ formation in conjunction with reduced total thromboxane $\left(\mathrm{TXA}_{2}\right.$ and $\left.\mathrm{TXA}_{3}\right)$, could favourably alter thrombotic, endothelial and vascular responses following dietary $\omega 3$ fatty acids.

Improvements in blood rheology ${ }^{104}$ and reduced PDGF-like proteins ${ }^{105}$ following $\omega 3$ fatty acids could contribute to a decrease in clinical atherothrombosis. $\omega 3$ Fatty acids have shown inconsistent and minor effects on measures of fibrinolysis and coagulability ${ }^{106,107 .}$

In spite of the in vitro evidence that $\omega 3$ fatty acids have antithrombotic effects, it is currently thought that any benefits are more likely related to their antiarrhythmic rather than antihrombotic effects ${ }^{106}$. This hypothesis is supported with the knowledge that cardiovascular clinical benefits of $\omega 3$ fatty acids have been noted with doses as low as 1g/day ${ }^{31,32}$ whilst changes in platelet aggregation have generally been observed at higher doses.

Mori et al ${ }^{108}$ showed that dietary fish and fish oils reduced platelet aggregation and platelet thromboxane formation. $\omega 3$ Fatty acid effects on platelet aggregation were also influenced by the background level of dietary fat, the source of the $\omega 3$ fatty acids and the agonist used to induce platelet aggregation. Dietary $\omega 3$ fatty acids reduced platelet $\mathrm{TXA}_{2}$ 
release from collagen-aggregated platelets ${ }^{108}$. Although platelet aggregation was reduced in response to all doses of collagen and PAF following $\omega 3$ fatty acids, the effect was more pronounced at doses of each agonist close to the threshold dose for aggregation.

\section{$\underline{\text { Independent Effects of EPA and DHA }}$}

In a double-blind placebo-controlled trial of parallel design, Woodman et al ${ }^{109}$ examined for differential effects of purified EPA and DHA on platelet function in treatedhypertensive Type 2 diabetic men and postmenopausal women. Participants were randomised to $4 \mathrm{~g}$ daily EPA, DHA or olive oil for 6 weeks. Relative to placebo, DHA but not EPA supplementation significantly reduced collagen-induced aggregation and $\mathrm{TXB}_{2}$ but there was no significant change in PAF-stimulated platelet aggregation.

\section{Inflammation}

$\omega 3$ Fatty acids have potent anti-inflammatory and immunomodulatory effects that operate through multiple mechanisms including attenuating formation of inflammatory eicosanoids and leukotrienes, cytokines, oxidative stress, and altering endothelial and cell-cell activation, and immune cell function ${ }^{53-55}$.

$\omega 3$ Fatty acids have been shown to alter production of the leukotrienes (LT) ${ }^{54}$. EPA is a preferred substrate of the lipoxygenase pathway leading to the production of the relatively inactive LTB5 at the expense of LTB4 which is derived from arachidonic acid; the latter is a potent chemotactic factor for leukocytes ${ }^{53-55}$. Increased generation of neutrophil-derived LTB5 has been demonstrated following intake of $\omega 3$ fatty acids in humans ${ }^{110,111}$. The formation of LTB5 in place of LTB4 following consumption of $\omega 3$ fatty acids likely plays an important role in attenuating the inflammatory process.

A number of studies have shown $\omega 3$ fatty acids reduce ex vivo formation of proinflammatory cytokines such as TNF- $\alpha$, IL-1 and IL-6 following stimulation of monocytes/lymphocytes with lipopolysaccharide ${ }^{53-55}$. In-vitro studies have also shown $\omega 3$ 
fatty acids decreased the expression of pro-inflammatory cytokines, cell-adhesion molecules and monocyte adhesion to endothelial cells ${ }^{112}$. DHA was more potent than EPA in inhibiting expression of vascular cell adhesion molecule-1 (VCAM-1), intercellular adhesion molecule1 (ICAM-1) and E-selectin, after stimulation. The EPA and DHA-induced attenuation in adhesion molecule expression was accompanied by decreased binding of human lymphocytes and monocytes to cytokine-stimulated endothelial cells ${ }^{112}$.

\section{Resolvins, Protectins and Maresins}

There is emerging evidence that resolution of inflammation is an active process accompanied by the biosynthesis of potent lipid mediators that stimulate resolution with consequent return to tissue homeostasis. Serhan et al ${ }^{56}$ have described several families of chemically and functionally distinct mediators, including E-series resolvins derived from EPA via P450 metabolism or aspirin-acetylated cyclooxygenase (COX-2), and D-series resolvins, protectins/neuroprotectins and maresins derived from DHA via lipoxygenase or aspirin acetylated COX-2 ${ }^{113-116}$. These mediators act via G-coupled protein receptors ${ }^{117}$ and have potent anti-inflammatory and pro-resolving actions ${ }^{118,119}$ that increase with time during the inflammatory process ${ }^{56,120}$. Studies have shown they reduce airway inflammation ${ }^{121}$, colitis ${ }^{122}$, arthritis ${ }^{123}$ and post-operative pain ${ }^{124}$. The resolvins from $\omega 3$ fatty acids are orders of magnitude more potent than the lipoxins derived from arachidonic acid.

Mas et al ${ }^{125}$ have shown that 18R/S-HEPE and 17R/S-HDHA, the resolvin and protectin pathway precursors, as well as the resolvins 17S-RvD2, 17S-RvD1 and 17R-RvD1, were increased in human plasma following $\omega 3$ fatty acid supplementation, at concentrations known to have potent anti-inflammatory effects.

\section{Effects on Plaque Stabilization}

The antithrombotic and anti-inflammatory effects of $\omega 3$ fatty acids play an important role in preventing plaque development and may assist in plaque stabilization. Thies et al ${ }^{126}$ 
showed that following supplementation, $\omega 3$ fatty acids were readily incorporated into the atherosclerotic plaque of patients with symptomatic carotid atherosclerotic disease undergoing carotid endarterectomy. The study showed that this incorporation associated with a reduced number of macrophages in the plaque and plaque morphology suggestive of increased stability. These findings could represent an important mechanism by which $\omega 3$ fatty acids reduce ischaemic cardiovascular events.

\section{Glucose Homeostasis}

Early reports suggested $\omega 3$ fatty acids adversely affected glycaemic control, particularly in Type 2 diabetic patients. However, these findings were likely related to the study design, the high dose of $\omega 3$ fatty acids employed, concomitant oral diabetic medication, the presence of obesity and/or insulin resistance, presence of other comorbidities such as hypertension, not controlling for background dietary intake during intervention, and duration of intervention ${ }^{127}$. Three meta-analyses comprising 26, 18 and 23 randomised controlled studies, have subsequently shown $\omega 3$ fatty acids have no overall effect on fasting glucose or glycated haemoglobin in patients with Type 2 diabetes ${ }^{127-129}$. In a meta-analysis of 11 randomized controlled trials comprising 618 individuals, $\omega 3$ fatty acids had no effect on insulin sensitivity, including in individuals with Type 2 diabetes ${ }^{130}$. Furthermore, a recent systematic review of 16 studies that included 540,184 individuals and 25,670 cases of incident diabetes mellitus showed fish and/or seafood consumption, or consumption of EPA+DHA, were not significantly associated with risk of diabetes ${ }^{131}$.

Two placebo-controlled trials have examined the differential effects of encapsulated purified EPA or DHA on plasma glucose and insulin in Type 2 diabetic patients ${ }^{60}$ and in mild dyslipidaemic men ${ }^{59}$. The data show that the effect of EPA and DHA on plasma glucose and insulin levels is dependent on the background condition of the individuals studied. In dyslipidaemic men Mori et al ${ }^{59}$ reported a borderline increase in fasting glucose with $4 \mathrm{~g}$ daily 
EPA, but no change with DHA. Fasting serum insulin increased relative to placebo after DHA, but not after EPA ${ }^{59}$. In contrast, Woodman et al ${ }^{60}$ showed In Type 2 diabetic patients that fasting glucose increased following $4 \mathrm{~g}$ daily EPA or DHA, but insulin and C-peptide were unaltered by either fatty acid ${ }^{60}$. Self-monitored blood glucose measured four times per day on four days of each week, increased following EPA and DHA in the first 3 weeks, but had returned to baseline by the sixth week of the intervention ${ }^{60} . \mathrm{HbA}_{1 \mathrm{c}}$, insulin secretion and insulin sensitivity were unaffected by EPA or DHA ${ }^{60}$.

\section{Oxidative Stress}

There has been concern that $\omega 3$ fatty acids may increase lipid peroxidation and oxidative stress. However, Mori et al showed that $\omega 3$ fatty acids decreased urinary $\mathrm{F}_{2^{-}}$ isoprostane excretion in patients with Type 2 diabetes consuming fish meals ${ }^{132} \cdot \mathrm{F}_{2^{-}}$ isoprostanes are lipid peroxidation products derived from the non-enzymatic free radical oxidation of arachidonic acid in membrane lipids and are considered the most reliable biomarkers of in vivo lipid peroxidative damage ${ }^{133}$.

Subsequent placebo controlled studies using purified EPA or DHA showed both fatty acids reduced urinary ${ }^{134,135}$ and plasma ${ }^{57} \mathrm{~F}_{2}$-isoprostanes in patients with Type 2 diabetes, and in overweight mildly dyslipidaemic men, respectively. Furthermore, the fall in plasma $\mathrm{F}_{2^{-}}$ isoprostanes was independent of changes in plasma arachidonic acid, EPA or DHA ${ }^{57}$. Barden et al ${ }^{136}$ demonstrated that cord plasma and urinary $F_{2}$-isoprostanes were reduced in infants whose mother received a $\omega 3$ fatty acid supplement during pregnancy.

A reduction in $\mathrm{F}_{2}$-isoprostanes has been confirmed in other studies in humans following $\omega 3$ fatty acids. Higdon et al ${ }^{137}$ demonstrated a fall in plasma $F_{2}$-isoprostanes in postmenopausal women, although these effects were eliminated after adjusting for plasma arachidonic acid concentrations. Nalsen et al ${ }^{138}$ showed in the KANWU study, a randomized multicenter trial in healthy subjects supplemented with fish oil or placebo, that $\omega 3$ fatty acids 
reduced plasma $\mathrm{F}_{2}$-isoprostanes. Quaggiotto et al ${ }^{139}$ showed plasma $\mathrm{F}_{2}$-isoprostanes were reduced in pigs fed high doses of $\omega 3$ fatty acids.

The mechanisms by which $\omega 3$ fatty acids attenuate oxidative stress are not known, but likely involve decreased leukocyte activation and immunomodulatory actions, a hypothesis supported by data showing changes in $\mathrm{F}_{2}$-isoprostanes significantly associated with changes in TNF- $\alpha^{134}$.

\section{The $\omega 3$ Index}

Harris and von Schacky ${ }^{140}$ have proposed that erythrocyte EPA+DHA, termed the Omega-3 Index, may be a marker for cardiovascular health and risk of fatal CHD. It has been suggested that an Omega-3 Index of $\geq 8 \%$ associates with cardioprotective effects whereas an index of $\leq 4 \%$ gives the least cardioprotection ${ }^{140}$. This hypothesis is supported by data from studies in patients with acute coronary syndrome ${ }^{141}$ and stable $\mathrm{CHD}^{142}$ that show the Omega3 Index inversely associated with risk for CHD and total mortality independently of traditional cardiovascular risk factors.

\section{RECOMMENDATIONS}

\section{Safety and potential adverse effects}

Consumption of $\omega 3$ fatty acid supplements does not associate with adverse effects other than occasional gastrointestinal upset and a "fishy burp". The latter is generally preventable by taking $\omega 3$ fatty acids capsules with a cold beverage and a meal. Concerns have been raised that high intakes of $\omega 3$ fatty acids could potentially increase the risk of bleeding when taken in conjunction with antiplatelet or anticoagulant medications. However, Bays ${ }^{143}$ in a review of studies concluded that there was little evidence of increased risk for clinically significant bleeding when $\omega 3$ fatty acid supplements are taken in combination with agents that may increase bleeding such as aspirin or warfarin. These findings were supported by Watson et al 
${ }^{144}$ who showed that high dose fish oil (up to $4 \mathrm{~g}$ daily) did not increase the risk of bleeding when taken with aspirin and the antiplatelet agent clopidogrel. Harris ${ }^{145}$ further concluded that on the basis of existing clinical data, the benefits of $\omega 3$ fatty acids more than outweigh any theoretical risks for bleeding. Bays ${ }^{143}$ added that clinicians should be mindful of increased bleeding as a theoretical possibility.

Some concerns have also been raised that $\omega 3$ fatty acids could increase the risk of bleeding during major surgery, particularly in individuals consuming high supplement doses. However, postoperative parenteral fish oil administration at a dose of $0.2 \mathrm{~g} / \mathrm{kg}$ body weight after major abdominal surgery did not result in clinically significant bleeding and was considered safe with regard to coagulation and platelet function ${ }^{146}$. Nonetheless some clinicians routinely advise patients to discontinue fish oil supplements 4-7 days prior to invasive procedures with the highest risk for bleeding complications. Postoperatively, clinicians should consider the cardiovascular advantages of recommencing $\omega 3$ fatty acid supplements in view of the fact that cardiovascular and thrombotic events are often common complications after major surgeries.

Some fish species may contain levels of methylmercury and environmental contaminants. These substances are present at low levels in fresh waters and oceans but accumulate in the aquatic food chain and are present at highest levels in predatory fish such as shark, swordfish, marlin and larger species of tuna, and marine mammals. The American Heart Association and other advisory bodies advise women who are either pregnant or may become pregnant, lactating women and young children, to limit their consumption of such fish species in order to minimize their exposure to these contaminants ${ }^{147}$.

\section{Guidelines for $\omega 3$ fatty acid intake}

Current guidelines from the American Heart Association ${ }^{147}$ and other global health agencies such as the World Health Organization, the European Society of Cardiology, the 
National Health and Medical Research Council of Australia, the United Kingdom Scientific Advisory Committee on Nutrition, and the International Society for the Study of Fatty Acids and Lipids, have made population-based dietary recommendations for $\omega 3$ fatty acids ${ }^{148}$. In general it has been suggested that individuals should consume approximately $500 \mathrm{mg} / \mathrm{day}$ of EPA and DHA ${ }^{149}$. This recommendation can be met by following the American Heart Association's dietary guidelines that suggest consumption of at least two $100 \mathrm{~g}$ serves of fish per week, preferably oil fish species such as fresh tuna, salmon, mackerel, herring and sardines ${ }^{147}$. Fish should be broiled or baked, but not fried ${ }^{20}$.

A practical recommendation for increasing $\omega 3$ fatty acid intake in the general population is to incorporate fish as part of a healthy diet that includes increased consumption of fruits and vegetables, and moderation of salt intake. Patients with CHD should be encouraged to increase their EPA and DHA consumption to approximately $1 \mathrm{~g}$ daily ${ }^{147}$, a figure based largely on data from clinical trials ${ }^{31}$. It has been suggested that $\omega 3$ fatty acid supplements at doses $2-4 \mathrm{~g} /$ day should be considered in combination with other lipid therapies in patients with hypertriglyceridaemia ${ }^{147}$. In view of the fact that the fetus relies on the mother for DHA, necessary for the development of the nervous system, pregnant and lactating

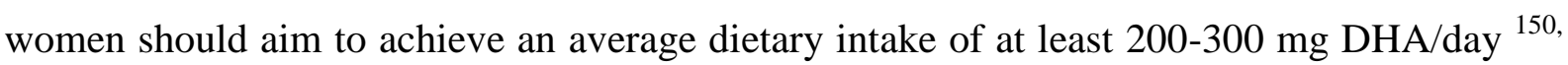
151. These doses of $\omega 3$ fatty acids are now achievable with the availability of high-quality encapsulated $\omega 3$ fatty acid supplements free of contaminants.

\section{CONCLUSIONS}

Current data support the concept that $\omega 3$ fatty acids beneficially influence a number of cardiometabolic risk factors. $\omega 3$ fatty acids have anti-atherosclerotic, antithrombotic and antiinflammatory actions. These effects likely explain the results from clinical trials that demonstrate $\omega 3$ fatty acids reduce mortality and morbidity in the setting of secondary 
prevention, particularly in those patients surviving a myocardial infarction or with heart failure. Recently published studies in which $\omega 3$ fatty acids have not shown benefit on cardiovascular endpoints are probably due to the fact that patients are now more likely to receive overall better medical care and optimal drug treatment. $\omega 3$ Fatty acids do not have adverse interactions with medications such as statins and other lipid-lowering drugs, or antihypertensive and antithrombotic medications. Several issues regarding $\omega 3$ fatty acids remain to be resolved, such as the optimal dose, the ratio of EPA to DHA, and their effectiveness in the setting of conventional drug therapy in different patient populations. Small doses of 1g/day are achievable with consumption of 2-3 oily fish meals per week. Higher doses up to at least $4 \mathrm{~g} /$ day have no clinically significant adverse effects and are achievable with consumption of numerous purified encapsulated preparations now readily available. Overall there is sufficient evidence that increased dietary $\omega 3$ fatty acids should be encouraged. In particular, fish should be considered an important component of a healthy diet and as a potential therapeutic modality in patients with coronary artery disease and those at heightened risk of cardiovascular disease ${ }^{152}$.

\section{ACKNOWLEDGEMENTS}

Aspects of the research work described from the author's laboratory presented in this review was supported by grants from the National Health \& Medical Research Council of Australia; the National Heart Foundation of Australia; the Fish Oil Test Materials Program of the National Institutes of Health/Department of Commerce, USA; and the Medical Research Foundation of Royal Perth Hospital, Perth, Western Australia. The author is supported in part by a Research Fellowship from the National Health and Medical Research Council (NHMRC) of Australia (1042255). 


\section{REFERENCES}

1. H. O. Bang, J. Dyerberg and A. B. Nielson, Plasma Lipid and Lipoprotein Pattern in Greenlandic West-Coast Eskimos, Lancet, 1971, 1, 1143-1146.

2. H. O. Bang, J. Dyerberg and N. Hjorne, Composition of Food Consumed by Greenland Eskimos, Acta Med Scand, 1976, 200, 69-73.

3. H. O. Bang, J. Dyerberg and H. M. Sinclair, The Composition of the Eskimo Food in Northwestern Greenland, Am J Clin Nutr, 1980, 33, 2657-2661.

4. M. Wada, C. J. DeLong, Y. H. Hong, C. J. Rieke, I. Song, R. S. Sidhu, C. Yuan, M. Warnock, A. H. Schmaier, C. Yokoyama, E. M. Smyth, S. J. Wilson, G. A. FitzGerald, R. M. Garavito, D. X. Sui, J. W. Regan and W. L. Smith, Enzymes and receptors of prostaglandin pathways with arachidonic acid-derived versus eicosapentaenoic acid-derived substrates and products, J Biol Chem, 2007, 282, 22254-22266.

5. S. P. Tull, C. M. Yates, B. H. Maskrey, V. B. O'Donnell, J. Madden, R. F. Grimble, P. C. Calder, G. B. Nash and G. E. Rainger, Omega-3 Fatty acids and inflammation: novel interactions reveal a new step in neutrophil recruitment, Plos Biol, 2009, 7, e1000177.

6. J. T. Brenna, N. Salem, A. J. Sinclair, S. C. Cunnane and Issfal, alpha-Linolenic acid supplementation and conversion to n-3 long-chain polyunsaturated fatty acids in humans, Prostag Leukotr Ess, 2009, 80, 85-91.

7. F. N. Hepburn, J. Exler and J. L. Weihrauch, Provisional tables on the content of omega-3 fatty acids and other fat components of selected foods, J Am Diet Assoc, 1986, 86, 788-793.

8. H. C. Bucher, P. Hengstler, C. Schindler and G. Meier, N-3 polyunsaturated fatty acids in coronary heart disease: a meta-analysis of randomized controlled trials, Am J Med, 2002, 112, 298-304.

9. K. He, Y. Q. Song, M. L. Daviglus, K. Liu, L. Van Horn, A. R. Dyer and P. Greenland, Accumulated evidence on fish consumption and coronary heart disease mortality - A meta-analysis of cohort studies, Circulation, 2004, 109, 2705-2711.

10. C. C. Wang, W. S. Harris, M. Chung, A. H. Lichtenstein, E. M. Balk, B. Kupelnick, H. S. Jordan and J. Lau, n-3 fatty acids from fish or fish-oil supplements, but not alpha-linolenic acid, benefit cardiovascular disease outcomes in primary- and secondary-prevention studies: a systematic review, Am J Clin Nutr, 2006, 84, 5-17.

11. S. P. Whelton, J. He, P. K. Whelton and P. Muntner, Meta-analysis of observational studies on fish intake and coronary heart disease, Am J Cardiol, 2004, 93, 1119-1123.

12. P. E. Marik and J. Varon, Omega-3 Dietary Supplements and the Risk of Cardiovascular Events: A Systematic Review, Clin Cardiol, 2009, 32, 365-372.

13. K. Musa-Veloso, M. A. Binns, A. Kocenas, C. Chung, H. Rice, H. Oppedal-Olsen, H. Lloyd and S. Lemke, Impact of low v. moderate intakes of long-chain n-3 fatty acids on risk of coronary heart disease, Brit J Nutr, 2011, 106, 1129-1141.

14. Y. T. Zhao, Q. Chen, Y. X. Sun, X. B. Li, P. Zhang, Y. Xu and J. H. Guo, Prevention of sudden cardiac death with omega-3 fatty acids in patients with coronary heart disease: a meta-analysis of randomized controlled trials, Ann Med, 2009, 41, 301-310.

15. E. C. Rizos, E. E. Ntzani, E. Bika, M. S. Kostapanos and M. S. Elisaf, Association Between Omega-3 Fatty Acid Supplementation and Risk of Major Cardiovascular Disease Events A Systematic Review and Meta-analysis, JAMA, 2012, 308, 10241033. 
16. S. Kotwal, M. Jun, D. Sullivan, V. Perkovic and B. Neal, Omega 3 Fatty Acids and Cardiovascular Outcomes Systematic Review and Meta-Analysis, Circ-Cardiovasc Qual, 2012, 5, 808-818.

17. S. M. Kwak, S. K. Myung, Y. J. Lee and H. G. Seo, Efficacy of omega-3 fatty acid supplements (eicosapentaenoic acid and docosahexaenoic acid) in the secondary prevention of cardiovascular disease: a meta-analysis of randomized, double-blind, placebo-controlled trials, Arch Intern Med, 2012, 172, 686-694.

18. E. B. Levitan, A. Wolk and M. A. Mittleman, Fish consumption, marine omega-3 fatty acids, and incidence of heart failure: a population-based prospective study of middleaged and elderly men, Eur Heart J, 2009, 30, 1495-1500.

19. L. Djousse, A. O. Akinkuolie, J. H. Y. Wu, E. L. Ding and J. M. Gaziano, Fish consumption, omega-3 fatty acids and risk of heart failure: A meta-analysis, Clin Nutr, 2012, 31, 846-853.

20. D. Mozaffarian, C. L. Bryson, R. N. Lemaitre, G. L. Burke and D. S. Siscovick, Fish intake and risk of incident heart failure, $J$ Am Coll Cardiol, 2005, 45, 2015-2021.

21. D. Mozaffarian, B. M. Psaty, E. B. Rimm, R. N. Lemaitre, G. L. Burke, M. F. Lyles, D. Lefkowitz and D. S. Siscovick, Fish intake and risk of incident atrial fibrillation, Circulation, 2004, 110, 368-373.

22. J. K. Virtanen, J. Mursu, S. Voutilainen and T. P. Tuomainen, Serum Long-Chain n-3 Polyunsaturated Fatty Acids and Risk of Hospital Diagnosis of Atrial Fibrillation in Men, Circulation, 2009, 120, 2315-2321.

23. J. H. Y. Wu, R. N. Lemaitre, I. B. King, X. L. Song, F. M. Sacks, E. B. Rimm, S. R. Heckbert, D. S. Siscovick and D. Mozaffarian, Association of Plasma Phospholipid Long-Chain Omega-3 Fatty Acids With Incident Atrial Fibrillation in Older Adults The Cardiovascular Health Study, Circulation, 2012, 125, 1084-U1071.

24. L. Frost and P. Vestergaard, n-3 Fatty acids consumed from fish and risk of atrial fibrillation or flutter: the Danish Diet, Cancer, and Health Study, Am J Clin Nutr, 2005, 81, 50-54.

25. N. N. Gronroos, A. M. Chamberlain, A. R. Folsom, E. Z. Soliman, S. K. Agarwal, J. A. Nettleton and A. Alonso, Fish, Fish-Derived n-3 Fatty Acids, and Risk of Incident Atrial Fibrillation in the Atherosclerosis Risk in Communities (ARIC) Study, PLoS One, 2012, 7.

26. R. G. Metcalf, G. V. Skuladottir, O. S. Indridason, T. R. Sullivan, L. Bjorgvinsdottir, P. Sanders, D. O. Arnar, R. A. Gibson, R. Heidarsdottir, L. G. Cleland, R. Palsson, A. L. Farquharson, G. D. Young and M. J. James, U-shaped relationship between tissue docosahexaenoic acid and atrial fibrillation following cardiac surgery, Eur J Clin Nutr, 2014, 68, 114-118.

27. T. A. Rix, A. M. Joensen, S. Riahi, S. Lundbye-Christensen, A. Tjonneland, E. B. Schmidt and K. Overvad, A U-shaped association between consumption of marine n-3 fatty acids and development of atrial fibrillation/atrial flutter--a Danish cohort study, Europace, 2014, DOI: 10.1093/europace/euu019.

28. K. He, Y. Q. Song, M. L. Daviglus, K. Liu, L. Van Horn, A. R. Dyer, U. Goldbourt and P. Greenland, Fish consumption and incidence of stroke - A meta-analysis of cohort studies, Stroke, 2004, 35, 1538-1542.

29. P. Xun, B. Qin, Y. Song, Y. Nakamura, T. Kurth, S. Yaemsiri, L. Djousse and K. He, Fish consumption and risk of stroke and its subtypes: accumulative evidence from a meta-analysis of prospective cohort studies, Eur J Clin Nutr, 2012, 66, 1199-1207.

30. M. L. Burr, J. F. Gilbert, R. M. Holliday, P. C. Elwood, A. M. Fehily, S. Rogers, P. M. Sweetnam and N. M. Deadman, Effects of Changes in Fat, Fish, and Fiber Intakes on 
Death and Myocardial Reinfarction - Diet and Reinfarction Trial (Dart), Lancet, 1989, 2, 757-761.

31. F. Valagussa, M. G. Franzosi, E. Geraci, N. Mininni, G. L. Nicolosi, M. Santini, L. Tavazzi, C. Vecchio, R. Marchioli, E. Bomba, C. Chieffo, A. P. Maggioni, C.

Schweiger, G. Tognoni, F. Barzi, A. V. Flamminio, R. M. Marfisi, M. Olivieri, C. Pera, A. Polidoro, E. Santoro, R. Zama, L. Pagliaro, E. Correale, A. Del Favero, U. Loi, E. Marubini, L. Campolo, A. Casari, G. Di Minno, M. B. Donati, M. Galli, M. Gattone, S. Garattini, M. Mancini, P. Marino, G. M. Santoro, C. Scardulla, G.

Specchia, A. Cericola, D. Di Gregorio, R. Di Mascio, G. Levantesi, L. Mantini, G. Mastrogiuseppe, C. Tucci, P. Mocarelli, R. Baldinelli, F. Ceriotti, A. Colonna, C. Cortese, G. Fortunato, C. Franzini, F. Gonano, M. S. Graziani and G.-P. Investigators, Dietary supplementation with n-3 polyunsaturated fatty acids and vitamin E after myocardial infarction: results of the GISSI-Prevenzione trial, Lancet, 1999, 354, 447455.

32. L. Tavazzi, A. P. Maggioni, R. Marchioli, S. Barlera, M. G. Franzosi, R. Latini, D. Lucci, G. L. Nicolosi, M. Porcu, G. Tognoni and G. H. Investigators, Effect of n-3 polyunsaturated fatty acids in patients with chronic heart failure (the GISSI-HF trial): a randomised, double-blind, placebo-controlled trial, Lancet, 2008, 372, 1223-1230.

33. M. Yokoyama, H. Origasa, M. Matsuzaki, Y. Matsuzawa, Y. Saito, Y. Ishikawa, S. Oikawa, J. Sasaki, H. Hishida, H. Itakura, T. Kita, A. Kitabatake, N. Nakaya, T. Sakata, K. Shimada, K. Shirato and J. Investigators, Effects of eicosapentaenoic acid on major coronary events in hypercholesterolaemic patients (JELIS): a randomised openlabel, blinded endpoint analysis, Lancet, 2007, 369, 1090-1098.

34. D. Mozaffarian, R. Marchioli, A. Macchia, M. G. Silletta, P. Ferrazzi, T. J. Gardner, R. Latini, P. Libby, F. Lombardi, P. T. O'Gara, R. L. Page, L. Tavazzi, G. Tognoni and O. Investigators, Fish Oil and Postoperative Atrial Fibrillation The Omega-3 Fatty Acids for Prevention of Post-operative Atrial Fibrillation (OPERA) Randomized Trial, JAMA, 2012, 308, 2001-2011.

35. J. Bosch, H. C. Gerstein, G. R. Dagenais, R. Diaz, L. Dyal, H. Jung, A. P. Maggiono, J. Probstfield, A. Ramachandran, M. C. Riddle, L. E. Ryden and S. Yusuf, n-3 Fatty Acids and Cardiovascular Outcomes in Patients with Dysglycemia, New Engl J Med, 2012, 367, 309-318.

36. M. C. Roncaglioni, M. Tombesi, F. Avanzini, S. Barlera, V. Caimi, P. Longoni, I. Marzona, V. Milani, M. G. Silletta, G. Tognoni, R. Marchioli and R. P. S. Collaborativ, n-3 Fatty Acids in Patients with Multiple Cardiovascular Risk Factors, New Engl J Med, 2013, 368, 1800-1808.

37. W. S. Harris, B. Assaad and W. C. Poston, Tissue omega-6/omega-3 fatty acid ratio and risk for coronary artery disease, Am J Cardiol, 2006, 98, 19i-26i.

38. E. B. Schmidt, H. Arnesen, R. de Caterina, L. H. Rasmussen and S. D. Kristensen, Marine n-3 polyunsaturated fatty acids and coronary heart disease - Part I. Background, epidemiology, animal data, effects on risk factors and safety, Thromb Res, 2005, 115, 163-170.

39. E. B. Schmidt, H. Arnesen, J. H. Christensen, L. H. Rasmussen, S. D. Kristensen and R. De Caterina, Marine n-3 polyunsaturated fatty acids and coronary heart disease Part II: Clinical trials and recommendations, Thromb Res, 2005, 115, 257-262.

40. T. A. Mori and L. J. Beilin, Long-chain omega 3 fatty acids, blood lipids and cardiovascular risk reduction, Curr Opin Lipidol, 2001, 12, 11-17.

41. D. Mozaffarian and J. H. Wu, Omega-3 fatty acids and cardiovascular disease: effects on risk factors, molecular pathways, and clinical events, J Am Coll Cardiol, 2011, 58, 2047-2067. 
42. L. J. Appel, E. R. Miller, A. J. Seidler and P. K. Whelton, Does Supplementation of Diet with Fish-Oil Reduce Blood-Pressure - a Metaanalysis of Controlled ClinicalTrials, Arch Int Med, 1993, 153, 1429-1438.

43. J. M. Geleijnse, E. J. Giltay, D. E. Grobbee, A. R. T. Donders and F. J. Kok, Blood pressure response to fish oil supplementation: metaregression analysis of randomized trials, J Hypertens, 2002, 20, 1493-1499.

44. T. A. Mori, V. Burke and L. J. Beilin, Dietary Fats and Blood Pressure, Elsevier, Philadelphia, 2007.

45. M. C. Morris, F. Sacks and B. Rosner, Does Fish-Oil Lower Blood-Pressure - a Metaanalysis of Controlled Trials, Circulation, 1993, 88, 523-533.

46. G. E. Mcveigh, G. M. Brennan, J. N. Cohn, S. M. Finkelstein, R. J. Hayes and G. D. Johnston, Fish-Oil Improves Arterial Compliance in Non-Insulin-Dependent DiabetesMellitus, Arterioscler Thromb, 1994, 14, 1425-1429.

47. P. Nestel, H. Shige, S. Pomeroy, M. Cehun, M. Abbey and D. Raederstorff, The n-3 fatty acids eicosapentaenoic acid and docosahexaenoic acid increase systemic arterial compliance in humans, Am J Clin Nutr, 2002, 76, 326-330.

48. J. P. Chin, Marine oils and cardiovascular reactivity, Prost, Leuk, Essent Fatty Acids, 1994, 50, 211-222.

49. T. A. Mori, G. F. Watts, V. Burke, E. Hilme, I. B. Puddey and L. J. Beilin, Differential effects of eicosapentaenoic acid and docosahexaenoic acid on vascular reactivity of the forearm microcirculation in hyperlipidemic, overweight men, Circulation, 2000, 102, 1264-1269.

50. W. S. Harris, n-3 fatty acids and lipoproteins: comparison of results from human and animal studies, Lipids, 1996, 31, 243-252.

51. W. S. Harris, n-3 fatty acids and serum lipoproteins: human studies, Am J Clin Nutr, 1997, 65, 1645S-1654S.

52. H. R. Knapp, Dietary fatty acids in human thrombosis and hemostasis, Am J Clin Nutr, 1997, 65, S1687-S1698.

53. P. C. Calder, The role of marine omega-3 (n-3) fatty acids in inflammatory processes, atherosclerosis and plaque stability, Mol Nutr Food Res, 2012, 56, 1073-1080.

54. P. C. Calder, Omega-3 polyunsaturated fatty acids and inflammatory processes: nutrition or pharmacology?, Brit J Clin Pharmacol, 2013, 75, 645-662.

55. T. A. Mori and L. J. Beilin, Omega-3 fatty acids and inflammation, Curr Atheroscler Rep, 2004, 6, 461-467.

56. C. N. Serhan and N. A. Petasis, Resolvins and protectins in inflammation resolution, Chem Rev, 2011, 111, 5922-5943.

57. E. Mas, R. J. Woodman, V. Burke, I. B. Puddey, L. J. Beilin, T. Durand and T. A. Mori, The omega-3 fatty acids EPA and DHA decrease plasma $\mathrm{F}(2)$-isoprostanes: Results from two placebo-controlled interventions, Free Radic Res, 2010, 44, 983990.

58. T. A. Mori and R. J. Woodman, The independent effects of eicosapentaenoic acid and docosahexaenoic acid on cardiovascular risk factors in humans, Curr Opin Clin Nutr Metab Care, 2006, 9, 95-104.

59. T. A. Mori, V. Burke, I. B. Puddey, G. F. Watts, D. N. O'Neal, J. D. Best and L. J. Beilin, Purified eicosapentaenoic and docosahexaenoic acids have differential effects on serum lipids and lipoproteins, LDL particle size, glucose, and insulin in mildly hyperlipidemic men, Am J Clin Nutr, 2000, 71, 1085-1094.

60. R. J. Woodman, T. A. Mori, V. Burke, I. B. Puddey, G. F. Watts and L. J. Beilin, Effects of purified eicosapentaenoic and docosahexaenoic acids on glycemic control, 
blood pressure, and serum lipids in type 2 diabetic patients with treated hypertension, Am J Clin Nutr, 2002, 76, 1007-1015.

61. W. S. Harris and D. Bulchandani, Why do omega-3 fatty acids lower serum triglycerides?, Curr Opin Lipidol, 2006, 17, 387-393.

62. A. J. Cussons, G. F. Watts, T. A. Mori and B. G. Stuckey, Omega-3 fatty acid supplementation decreases liver fat content in polycystic ovary syndrome: a randomized controlled trial employing proton magnetic resonance spectroscopy, $J$ Clin Endocrinol Metab, 2009, 94, 3842-3848.

63. T. A. Mori, D. Q. Bao, V. Burke, I. B. Puddey, G. F. Watts and L. J. Beilin, Dietary fish as a major component of a weight-loss diet: effect on serum lipids, glucose, and insulin metabolism in overweight hypertensive subjects, Am J Clin Nutr, 1999, 70, 817-825.

64. R. J. Woodman, T. A. Mori, V. Burke, I. B. Puddey, G. F. Watts, J. D. Best and L. J. Beilin, Docosahexaenoic acid but not eicosapentaenoic acid increases LDL particle size in treated hypertensive type 2 diabetic patients, Diabetes Care, 2003, 26, 253.

65. J. Hulthe, L. Bokemark, J. Wikstrand and B. Fagerberg, The metabolic syndrome, LDL particle size, and atherosclerosis - The atherosclerosis and insulin resistance (AIR) study, Arterioscl Throm Vas, 2000, 20, 2140-2147.

66. S. Lahdenpera, M. Syvanne, J. Kahri and M. R. Taskinen, Regulation of low-density lipoprotein particle sire distribution in NIDDM and coronary disease: Importance of serum triglycerides, Diabetologia, 1996, 39, 453-461.

67. D. C. Chan, G. F. Watts, T. A. Mori, P. H. Barrett, L. J. Beilin and T. G. Redgrave, Factorial study of the effects of atorvastatin and fish oil on dyslipidaemia in visceral obesity, Eur J Clin Invest, 2002, 32, 429-436.

68. R. S. Dokholyan, C. M. Albert, L. J. Appel, N. R. Cook, P. Whelton and C. H. Hennekens, A trial of omega-3 fatty acids for prevention of hypertension, Am J Cardiol, 2004, 93, 1041-1043.

69. H. O. Dickinson, J. M. Mason, D. J. Nicolson, F. Campbell, F. R. Beyer, J. V. Cook, B. Williams and G. A. Ford, Lifestyle interventions to reduce raised blood pressure: a systematic review of randomized controlled trials, J Hypertens, 2006, 24, 215-233.

70. L. Cobiac, P. J. Nestel, L. M. Wing and P. R. Howe, A low-sodium diet supplemented with fish oil lowers blood pressure in the elderly, J Hypertens, 1992, 10, 87-92.

71. P. Singer, S. Melzer, M. Goschel and S. Augustin, Fish Oil Amplifies the Effect of Propranolol in Mild Essential-Hypertension, Hypertension, 1990, 16, 682-691.

72. Y. K. Lungershausen, M. Abbey, P. J. Nestel and P. R. Howe, Reduction of blood pressure and plasma triglycerides by omega-3 fatty acids in treated hypertensives, $J$ Hypertens, 1994, 12, 1041-1045.

73. D. Q. Bao, T. A. Mori, V. Burke, I. B. Puddey and L. J. Beilin, Effects of dietary fish and weight reduction on ambulatory blood pressure in overweight hypertensives, Hypertension, 1998, 32, 710-717.

74. T. A. Mori, D. Q. Bao, V. Burke, I. B. Puddey and L. J. Beilin, Docosahexaenoic acid but not eicosapentaenoic acid lowers ambulatory blood pressure and heart rate in humans, Hypertension, 1999, 34, 253-260.

75. S. Grimsgaard, K. H. Bonaa, J. B. Hansen and E. S. P. Myhre, Effects of highly purified eicosapentaenoic acid and docosahexaenoic acid on hemodynamics in humans, Am J Clin Nutr, 1998, 68, 52-59.

76. Z. M. Chu, K. Yin and L. J. Beilin, Fish oil feeding selectively attenuates contractile responses to noradrenaline and electrical stimulation in the perfused mesenteric resistance vessels of spontaneously hypertensive rats, Clin Exp Pharmacol Physiol, 1992, 19, 177-181. 
77. K. Yin, Z. M. Chu and L. J. Beilin, Blood pressure and vascular reactivity changes in spontaneously hypertensive rats fed fish oil, Br J Pharmacol, 1991, 102, 991-997.

78. J. P. Chin, A. P. Gust and A. M. Dart, Indomethacin inhibits the effects of dietary supplementation with marine oils on vasoconstriction of human forearm resistance vessels in vivo, J Hypertens, 1993, 11, 1229-1234.

79. J. P. F. Chin and A. M. Dart, Therapeutic Restoration of Endothelial Function in Hypercholesterolemic Subjects - Effect of Fish Oils, Clin Exp Pharmacol Physiol, 1994, 21, 749-755.

80. G. E. Mcveigh, G. M. Brennan, G. D. Johnston, B. J. Mcdermott, L. T. Mcgrath, W. R. Henry, J. W. Andrews and J. R. Hayes, Dietary Fish Oil Augments Nitric-Oxide Production or Release in Patients with Type-2 (Non-Insulin-Dependent) DiabetesMellitus, Diabetologia, 1993, 36, 33-38.

81. M. B. Engler, M. M. Engler and P. C. Ursell, Vasorelaxant properties of n-3 polyunsaturated fatty acids in aortas from spontaneously hypertensive and normotensive rats, J cardiovasc Risk, 1994, 1, 75-80.

82. P. McLennan, P. Howe, M. Abeywardena, R. Muggli, D. Raederstorff, M. Mano, T. Rayner and R. Head, The cardiovascular protective role of docosahexaenoic acid, Eur J Pharmacol, 1996, 300, 83-89.

83. W. S. Harris, G. S. Rambjor, S. L. Windsor and D. Diederich, n-3 fatty acids and urinary excretion of nitric oxide metabolites in humans, Am J Clin Nutr, 1997, 65, 459-464.

84. M. Hashimoto, M. S. Hossain, H. Yamasaki, K. Yazawa and S. Masumura, Effects of eicosapentaenoic acid and docosahexaenoic acid on plasma membrane fluidity of aortic endothelial cells, Lipids, 1999, 34, 1297-1304.

85. K. Yin, Z. M. Chu and L. J. Beilin, Study of Mechanisms of Glucocorticoid Hypertension in Rats - Endothelial Related Changes and Their Amelioration by Dietary Fish Oils, Brit J Pharmacol, 1992, 106, 435-442.

86. J. P. F. Chin and A. M. Dart, How Do Fish Oils Affect Vascular Functions, Clin Exp Pharmacol Physiol, 1995, 22, 71-81.

87. P. L. Fox and P. E. Dicorleto, Fish Oils Inhibit Endothelial-Cell Production of Platelet-Derived Growth-Factor Like Protein, Science, 1988, 241, 453-456.

88. V. B. Schini, W. Durante, E. Elizondo, T. Scottburden, D. C. Junquero, A. I. Schafer and P. M. Vanhoutte, The Induction of Nitric-Oxide Synthase Activity Is Inhibited by Tgf-Beta-1, Pdgfab and Pdgfbb in Vascular Smooth-Muscle Cells, Eur J Pharmacol, 1992, 216, 379-383.

89. M. Hashimoto, K. Shinozuka, S. Gamoh, Y. Tanabe, M. S. Hossain, Y. M. Kwon, N. Hata, Y. Misawa, M. Kunitomo and S. Masumura, The hypotensive effect of docosahexaenoic acid is associated with the enhanced release of ATP from the caudal artery of aged rats, $J$ Nutr, 1999, 129, 70-76.

90. R. Cernes, R. Zimlichman and M. Shargorodsky, Arterial elasticity in cardiovascular disease: Focus on hypertension, metabolic syndrome and diabetes, Adv Cardiol, 2008, 45, 65-81.

91. M. P. Pase, N. A. Grima and J. Sarris, Do long-chain n-3 fatty acids reduce arterial stiffness? A meta-analysis of randomised controlled trials, Brit J Nutr, 2011, 106, 974980.

92. W. B. Kannel, C. Kannel, R. S. Paffenbarger, Jr. and L. A. Cupples, Heart rate and cardiovascular mortality: the Framingham Study, Am Heart J, 1987, 113, 1489-1494.

93. D. Mozaffarian, A. Geelen, I. A. Brouwer, J. M. Geleijnse, P. L. Zock and M. B. Katan, Effect of fish oil on heart rate in humans - A meta-analysis of randomized controlled trials, Circulation, 2005, 112, 1945-1952. 
94. A. Leaf, J. X. Kang, Y. F. Xiao and G. E. Billman, Clinical prevention of sudden cardiac death by $n-3$ polyunsaturated fatty acids and mechanism of prevention of arrhythmias by n-3 fish oils, Circulation, 2003, 107, 2646-2652.

95. J. H. Christensen, n-3 fatty acids and the risk of sudden cardiac death - Emphasis on heart rate variability, Dan Med Bull, 2003, 50, 347-367.

96. J. H. Christensen and E. B. Schmidt, N-3 fatty acids and the risk of sudden cardiac death, Lipids, 2001, 36, S115-S118.

97. S. Balanescu, A. D. Corlan, M. Dorobantu and L. Gherasim, Prognostic value of heart rate variability after acute myocardial infarction, Med Sci Monitor, 2004, 10, Cr307Cr315.

98. J. M. Dekker, R. S. Crow, A. R. Folsom, P. J. Hannan, D. Liao, C. A. Swenne and E. G. Schouten, Low heart rate variability in a 2-minute rhythm strip predicts risk of coronary heart disease and mortality from several causes - The ARIC study, Circulation, 2000, 102, 1239-1244.

99. J. M. Dekker, E. G. Schouten, P. Klootwijk, J. Pool, C. A. Swenne and D. Kromhout, Heart rate variability from short electrocardiographic recordings predicts mortality from all causes in middle-aged and elderly men - The zutphen study, Am J Epidemiol, 1997, 145, 899-908.

100. W. Xin, W. Wei and X. Y. Li, Short-term effects of fish-oil supplementation on heart rate variability in humans: a meta-analysis of randomized controlled trials, Am J Clin Nutr, 2013, 97, 926-935.

101. S. Fischer and P. C. Weber, Thromboxane-A3 (Txa3) Is Formed in Human-Platelets after Dietary Eicosapentaenoic Acid (C2o-5-Omega-3), Biochem Bioph Res Com, 1983, 116, 1091-1099.

102. H. R. Knapp, I. A. Reilly, P. Alessandrini and G. A. FitzGerald, In vivo indexes of platelet and vascular function during fish-oil administration in patients with atherosclerosis, $N$ Engl J Med, 1986, 314, 937-942.

103. S. Fischer and P. C. Weber, Prostaglandin-I3 Is Formed Invivo in Man after Dietary Eicosapentaenoic Acid, Nature, 1984, 307, 165-168.

104. I. J. Cartwright, A. G. Pockley, J. H. Galloway, M. Greaves and F. E. Preston, The Effects of Dietary Omega-3 Poly-Unsaturated Fatty-Acids on Erythrocyte-Membrane Phospholipids, Erythrocyte Deformability and Blood-Viscosity in Healthy-Volunteers, Atherosclerosis, 1985, 55, 267-281.

105. C. von Schacky, K. Baumann and P. Angerer, The effect of n-3 fatty acids on coronary atherosclerosis: Results from SCIMO, an angiographic study, background and implications, Lipids, 2001, 36, S99-S102.

106. S. D. Kristensen, A. M. B. Iversen and E. B. Schmidt, n-3 polyunsaturated fatty acids and coronary thrombosis, Lipids, 2001, 36, S79-S82.

107. A. H. Lichtenstein, Remarks on clinical data concerning dietary supplements that affect antithrombotic therapy, Thromb Res, 2005, 117, 71-73.

108. T. A. Mori, L. J. Beilin, V. Burke, J. Morris and J. Ritchie, Interactions between dietary fat, fish, and fish oils and their effects on platelet function in men at risk of cardiovascular disease, Arterioscler Thromb Vasc Biol, 1997, 17, 279-286.

109. R. J. Woodman, T. A. Mori, V. Burke, I. B. Puddey, A. Barden, G. F. Watts and L. J. Beilin, Effects of purified eicosapentaenoic acid and docosahexaenoic acid on platelet, fibrinolytic and vascular function in hypertensive type 2 diabetic patients, Atherosclerosis, 2003, 166, 85-93.

110. T. H. Lee, R. L. Hoover, J. D. Williams, R. I. Sperling, J. Ravalese, 3rd, B. W. Spur, D. R. Robinson, E. J. Corey, R. A. Lewis and K. F. Austen, Effect of dietary enrichment with eicosapentaenoic and docosahexaenoic acids on in vitro neutrophil 
and monocyte leukotriene generation and neutrophil function, $N$ Engl J Med, 1985, 312, 1217-1224.

111. T. A. Mori, R. Vandongen, F. Mahanian and A. Douglas, Plasma lipid levels and platelet and neutrophil function in patients with vascular disease following fish oil and olive oil supplementation, Metabolism, 1992, 41, 1059-1067.

112. R. De Caterina, J. K. Liao and P. Libby, Fatty acid modulation of endothelial activation, Am J Clin Nutr, 2000, 71, 213s-223s.

113. G. Bannenberg, M. Arita and C. N. Serhan, Endogenous receptor agonists: resolving inflammation, ScientificWorldJournal, 2007, 7, 1440-1462.

114. C. N. Serhan, Novel eicosanoid and docosanoid mediators: resolvins, docosatrienes, and neuroprotectins, Curr Opin Clin Nutr Metab Care, 2005, 8, 115-121.

115. C. N. Serhan, Novel omega -- 3-derived local mediators in anti-inflammation and resolution, Pharmacol Ther, 2005, 105, 7-21.

116. C. N. Serhan, S. D. Brain, C. D. Buckley, D. W. Gilroy, C. Haslett, L. A. O'Neill, M. Perretti, A. G. Rossi and J. L. Wallace, Resolution of inflammation: state of the art, definitions and terms, Faseb J, 2007, 21, 325-332.

117. C. N. Serhan and N. Chiang, Resolution phase lipid mediators of inflammation: agonists of resolution, Curr Opin Pharmacol, 2013, 13, 632-640.

118. R. R. Ji, Z. Z. Xu, G. Strichartz and C. N. Serhan, Emerging roles of resolvins in the resolution of inflammation and pain, Trends Neurosci, 2011, 34, 599-609.

119. C. N. Serhan, N. Chiang and T. E. Van Dyke, Resolving inflammation: dual antiinflammatory and pro-resolution lipid mediators, Nat Rev Immunol, 2008, 8, 349-361.

120. I. Tabas, Macrophage death and defective inflammation resolution in atherosclerosis, Nat Rev Immunol, 2010, 10, 36-46.

121. O. Haworth, M. Cernadas, R. Yang, C. N. Serhan and B. D. Levy, Resolvin E1 regulates interleukin 23, interferon-gamma and lipoxin A4 to promote the resolution of allergic airway inflammation, Nat Immunol, 2008, 9, 873-879.

122. A. F. Bento, R. F. Claudino, R. C. Dutra, R. Marcon and J. B. Calixto, Omega-3 fatty acid-derived mediators 17(R)-hydroxy docosahexaenoic acid, aspirin-triggered resolvin D1 and resolvin D2 prevent experimental colitis in mice, J Immunol, 2011, 187, 1957-1969.

123. Z. Z. Xu and R. R. Ji, Resolvins are potent analgesics for arthritic pain, $B r J$ Pharmacol, 2011, 164, 274-277.

124. L. Huang, C. F. Wang, C. N. Serhan and G. Strichartz, Enduring prevention and transient reduction of postoperative pain by intrathecal resolvin D1, Pain, 2011, 152, 557-565.

125. E. Mas, K. D. Croft, P. Zahra, A. Barden and T. A. Mori, Resolvins D1, D2, and other mediators of self-limited resolution of inflammation in human blood following n-3 fatty acid supplementation, Clin Chem, 2012, 58, 1476-1484.

126. F. Thies, J. M. C. Garry, P. Yaqoob, K. Rerkasem, J. Williams, C. P. Shearman, P. J. Gallagher, P. C. Calder and R. F. Grimble, Association of n-3 polyunsaturated fatty acids with stability of atherosclerotic plaques: a randomised controlled trial, Lancet, 2003, 361, 477-485.

127. C. E. Friedberg, M. J. F. M. Janssen, R. J. Heine and D. E. Grobbee, Fish oil and glycemic control in diabetes - A meta-analysis, Diabetes Care, 1998, 21, 494-500.

128. J. Hartweg, R. Perera, V. Montori, S. Dinneen, H. A. W. Neil and A. Farmer, Omega3 polyunsaturated fatty acids (PUFA) for type 2 diabetes mellitus, Cochrane Db Syst Rev, 2008, DOI: Artn Cd003205 Doi 10.1002/14651858.Cd003205.Pub2. 
129. V. M. Montori, A. Farmer, P. C. Wollan and S. F. Dinneen, Fish oil supplementation in type 2 diabetes - A quantitative systematic review, Diabetes Care, 2000, 23, 14071415.

130. A. O. Akinkuolie, J. S. Ngwa, J. B. Meigs and L. Djousse, Omega-3 polyunsaturated fatty acid and insulin sensitivity: A meta-analysis of randomized controlled trials, Clin Nutr, 2011, 30, 702-707.

131. J. H. Y. Wu, R. Micha, F. Imamura, A. Pan, M. L. Biggs, O. Ajaz, L. Djousse, F. B. $\mathrm{Hu}$ and D. Mozaffarian, Omega-3 fatty acids and incident type 2 diabetes: a systematic review and meta-analysis, Brit J Nutr, 2012, 107, S214-S227.

132. T. A. Mori, D. W. Dunstan, V. Burke, K. D. Croft, J. H. Rivera, L. J. Beilin and I. B. Puddey, Effect of dietary fish and exercise training on urinary F2-isoprostane excretion in non-insulin-dependent diabetic patients, Metabolism, 1999, 48, 14021408.

133. G. L. Milne, H. Yin, K. D. Hardy, S. S. Davies and L. J. Roberts, 2nd, Isoprostane generation and function, Chem Rev, 2011, 111, 5973-5996.

134. T. A. Mori, R. J. Woodman, V. Burke, I. B. Puddey, K. D. Croft and L. J. Beilin, Effect of eicosapentaenoic acid and docosahexaenoic acid on oxidative stress and inflammatory markers in treated-hypertensive type 2 diabetic subjects, Free Radic Biol Med, 2003, 35, 772-781.

135. T. A. Mori, I. B. Puddey, V. Burke, K. D. Croft, D. W. Dunstan, J. H. Rivera and L. J. Beilin, Effect of omega 3 fatty acids on oxidative stress in humans: GC-MS measurement of urinary F2-isoprostane excretion, Redox Rep, 2000, 5, 45-46.

136. A. E. Barden, T. A. Mori, J. A. Dunstan, A. L. Taylor, C. A. Thornton, K. D. Croft, L. J. Beilin and S. L. Prescott, Fish oil supplementation in pregnancy lowers F2isoprostanes in neonates at high risk of atopy, Free Radic Res, 2004, 38, 233-239.

137. J. V. Higdon, J. K. Liu, S. H. Du, J. D. Morrow, B. N. Ames and R. C. Wander, Supplementation of postmenopausal women with fish oil rich in eicosapentaenoic acid and docosahexaenoic acid is not associated with greater in vivo lipid peroxidation compared with oils rich in oleate and linoleate as assessed by plasma malondialdehyde and F-2-isoprostanes, Am J Clin Nutr, 2000, 72, 714-722.

138. C. Nalsen, B. Vessby, L. Berglund, M. Uusitupa, K. Hermansen, G. Riccardi, A. Rivellese, L. Storlien, A. Erkkila, S. Yla-Herttuala, L. Tapsell and S. Basu, Dietary (n3) fatty acids reduce plasma F-2-isoprostanes but not prostaglandin F-2 alpha in healthy humans, J Nutr, 2006, 136, 1222-1228.

139. P. Quaggiotto, J. W. Leitch, J. Falconer, R. N. Murdoch and M. L. Garg, Plasma F-2 alpha-isoprostane levels are lowered in pigs fed an (n-3) polyunsaturated fatty acid supplemented diet following occlusion of the left anterior descending coronary artery, Nutr Res, 2000, 20, 675-684.

140. W. S. Harris and C. Von Schacky, The Omega-3 Index: a new risk factor for death from coronary heart disease?, Prev Med, 2004, 39, 212-220.

141. R. C. Block, W. S. Harris, K. J. Reid, S. A. Sands and J. A. Spertus, EPA and DHA in blood cell membranes from acute coronary syndrome patients and controls, Atherosclerosis, 2008, 197, 821-828.

142. J. V. Pottala, S. Garg, B. E. Cohen, M. A. Whooley and W. S. Harris, Blood Eicosapentaenoic and Docosahexaenoic Acids Predict All-Cause Mortality in Patients With Stable Coronary Heart Disease The Heart and Soul Study, Circ-Cardiovasc Qual, 2010, 3, 406-412.

143. H. E. Bays, Safety considerations with omega-3 fatty acid therapy, Am J Cardiol, 2007, 99, 35C-43C. 
144. P. D. Watson, P. S. Joy, C. Nkonde, S. E. Hessen and D. G. Karalis, Comparison of bleeding complications with omega-3 fatty acids + aspirin + clopidogrel--versus-aspirin + clopidogrel in patients with cardiovascular disease, Am J Cardiol, 2009, 104, 1052-1054.

145. W. S. Harris, Expert opinion: omega-3 fatty acids and bleeding-cause for concern?, Am J Cardiol, 2007, 99, 44C-46C.

146. A. R. Heller, S. Fischer, T. Rossel, S. Geiger, G. Siegert, M. Ragaller, T. Zimmermann and $\mathrm{T}$. Koch, Impact of n-3 fatty acid supplemented parenteral nutrition on haemostasis patterns after major abdominal surgery, Brit J Nutr, 2002, 87, S95S101.

147. P. M. Kris-Etherton, W. S. Harris, L. J. Appel and N. Comm, Fish consumption, fish oil, omega-3 fatty acids, and cardiovascular disease, Circulation, 2002, 106, 27472757.

148. M. Lucas, G. Asselin, M. Plourde, S. C. Cunnane, E. Dewailly and S. Dodin, n-3 Fatty acid intake from marine food products among Quebecers: comparison to worldwide recommendations, Public Health Nutr, 2010, 13, 63-70.

149. S. K. Gebauer, T. L. Psota, W. S. Harris and P. M. Kris-Etherton, n-3 fatty acid dietary recommendations and food sources to achieve essentiality and cardiovascular benefits, Am J Clin Nutr, 2006, 83, 1526s-1535s.

150. B. Koletzko, I. Cetin, J. T. Brenna and P. Grp, Dietary fat intakes for pregnant and lactating women, Brit J Nutr, 2007, 98, 873-877.

151. A. P. Simopoulos, A. Leaf and N. Salem, Jr., Workshop statement on the essentiality of and recommended dietary intakes for Omega-6 and Omega-3 fatty acids, Prost, Leuk, Essent Fatty Acids, 2000, 63, 119-121.

152. D. M. Lloyd-Jones, Y. L. Hong, D. Labarthe, D. Mozaffarian, L. J. Appel, L. Van Horn, K. Greenlund, S. Daniels, G. Nichol, G. F. Tomaselli, D. K. Arnett, G. C. Fonarow, P. M. Ho, M. S. Lauer, F. A. Masoudi, R. M. Robertson, V. Roger, L. H. Schwamm, P. Sorlie, C. W. Yancy, W. D. Rosamond and A. H. A. S. Plannin, Defining and Setting National Goals for Cardiovascular Health Promotion and Disease Reduction The American Heart Association's Strategic Impact Goal Through 2020 and Beyond, Circulation, 2010, 121, 586-613. 


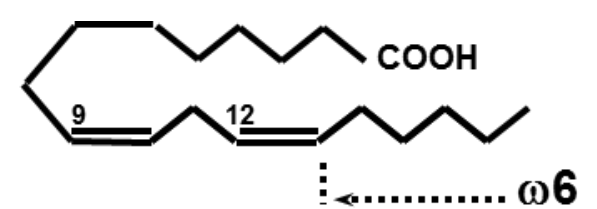

Linoleic Acid (18:2 $\omega 6)$

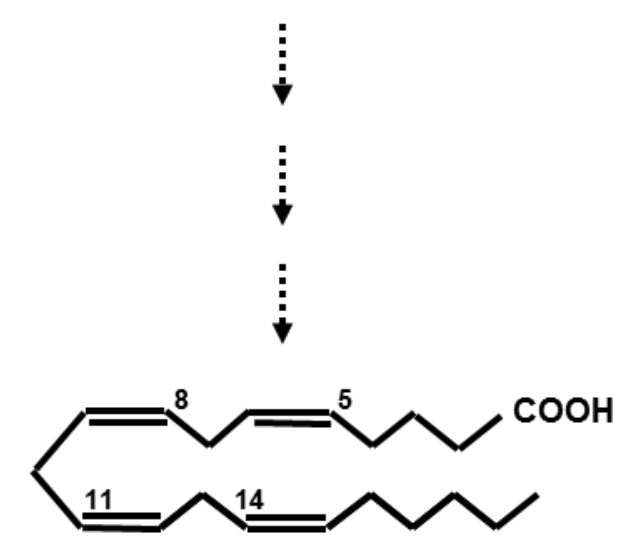

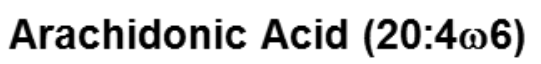

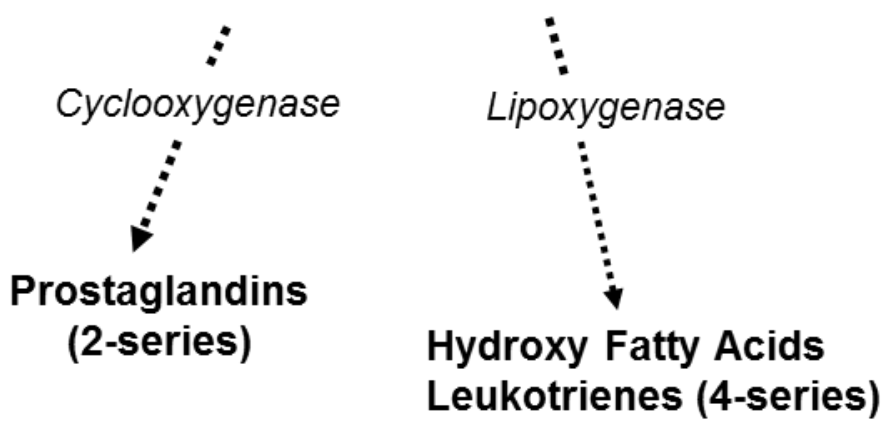

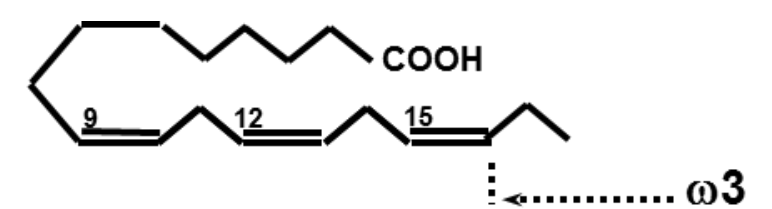

$\alpha$ - Linolenic Acid (18:3 $\omega 3)$

\section{$\triangle{ }^{6}$ Desaturase \\ $+2 C$ Elongation \\ $\Delta^{5}$ Desaturase}
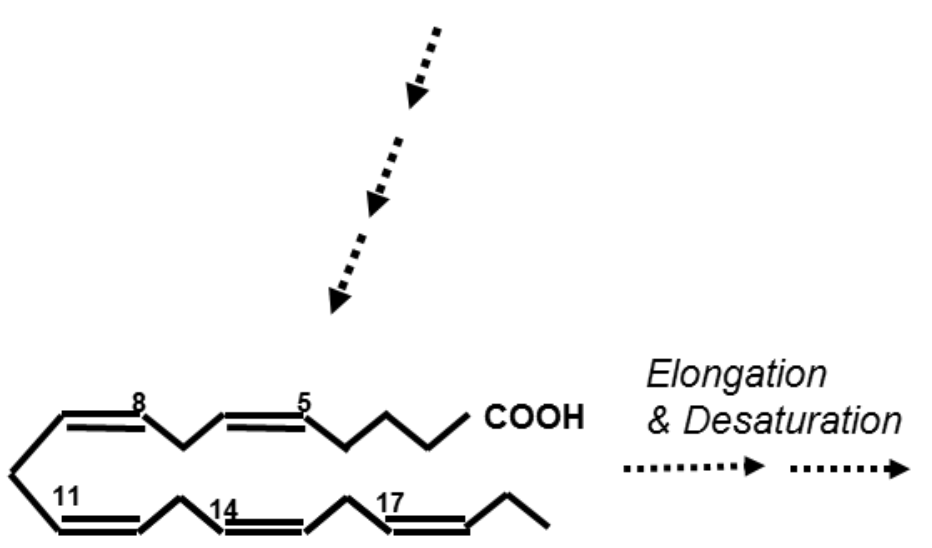

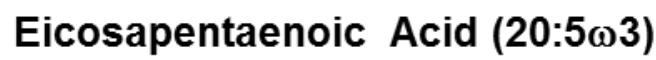

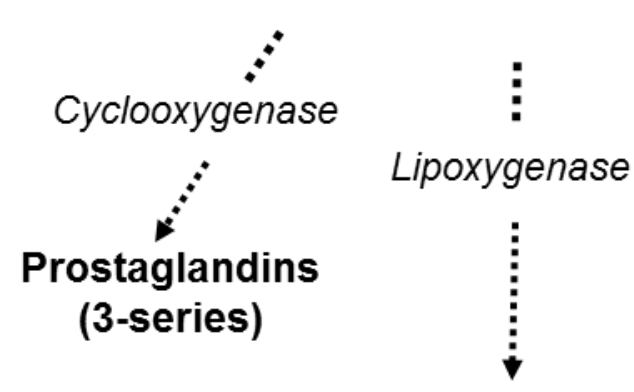

Hydroxy Fatty Acids Leukotrienes (5-series)

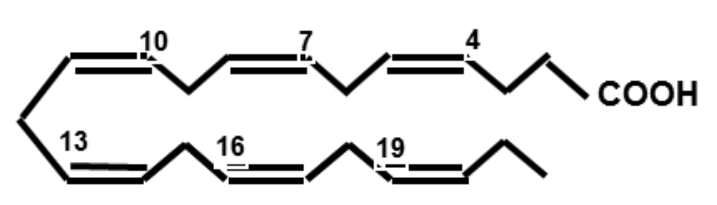

Docosahexaenoic Acid (22:6ஸ3)

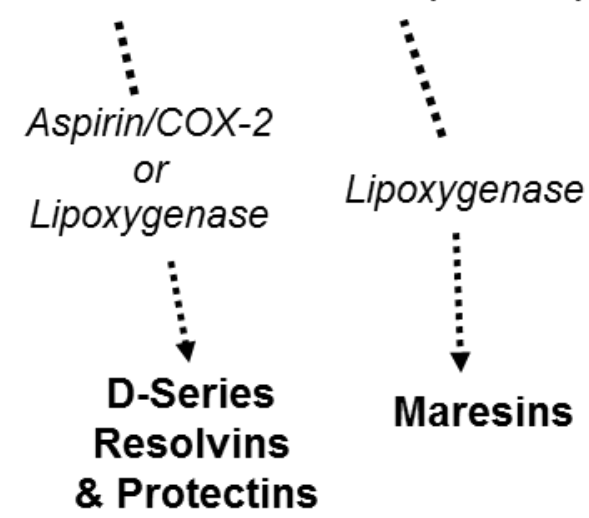

